San Jose State University

SJSU ScholarWorks

Master's Theses

Master's Theses and Graduate Research

Summer 2010

\title{
The effects of Bordetella pertussis on dendritic cell imprinting of CD4+ T cells
}

Sana Waheed

San Jose State University

Follow this and additional works at: https://scholarworks.sjsu.edu/etd_theses

\section{Recommended Citation}

Waheed, Sana, "The effects of Bordetella pertussis on dendritic cell imprinting of CD4+ T cells" (2010). Master's Theses. 3837.

DOI: https://doi.org/10.31979/etd.5ehv-ca54

https://scholarworks.sjsu.edu/etd_theses/3837

This Thesis is brought to you for free and open access by the Master's Theses and Graduate Research at SJSU ScholarWorks. It has been accepted for inclusion in Master's Theses by an authorized administrator of SJSU ScholarWorks. For more information, please contact scholarworks@sjsu.edu. 
THE EFFECTS OF BORDETELLA PERTUSSIS ON DENDRITIC CELL IMPRINTING

\title{
OF CD4+ T CELLS
}

\author{
A Thesis \\ Presented to \\ The Faculty of the Department of Biological Sciences \\ San José State University \\ In Partial Fulfillment \\ of the Requirements for the Degree \\ Master of Science
}

by

Sana Waheed

August 2010 
(C) 2010

Sana Waheed

ALL RIGHTS RESERVED 
The Designated Thesis Committee Approves the Thesis Titled

THE EFFECTS OF BORDETELLA PERTUSSIS ON DENDRITIC CELL IMPRINTING

OF CD4+ T CELLS

by

Sana Waheed

APPROVED FOR THE DEPARTMENT OF BIOLOGICAL SCIENCES

SAN JOSÉ STATE UNIVERSITY

August 2010

Dr. Tzvia Abramson

Department of Biological Sciences

Dr. John Boothby

Department of Biological Sciences

Dr. Kenneth Youngman

Department of Biological Sciences 


\section{ABSTRACT \\ THE EFFECTS OF BORDETELLA PERTUSSIS ON DENDRITIC CELL IMPRINTING OF CD4+ T CELLS \\ by Sana Waheed}

Bordetella pertussis is an aerobic gram-negative bacterial pathogen that causes the human respiratory disease whooping cough. Despite widespread vaccination, whooping cough is reemerging due to decreased vaccine efficacy. One of the hallmarks of infection is lymphocytosis, which is induced by the pertussis toxin. Lymphocytes such as CD4+ T cells navigate to infected tissues through surface-trafficking molecules, which are imprinted during their interaction with tissue-associated dendritic cells. We hypothesized that the pertussis toxin affects the imprinting process resulting in altered expression of trafficking molecules on CD4+ T cells. We tested this hypothesis using a mouse model of infection. Imprinting levels on CD4+ T cells were compared to Bordetella parapertussis, a related strain that lacks pertussis toxin. Our results indicated that 5 days post-infection, the percentage of lung dendritic cells increased and adopted a mature phenotype (displaying an increased capability to migrate and present antigen to T cells) in response to $B$. pertussis infection, and there was an overall downregulation of trafficking molecules on CD4+ T cells. However, 25 days post-infection with $B$. pertussis, dendritic cells continued to express elevated levels of MHC class II, and the expression of trafficking markers on CD4+ T cells also increased compared to uninfected controls. These results enable identification of molecules that are specific for lymphocyte trafficking to the respiratory airways and contribute to knowledge useful in the development of better vaccines. 


\section{ACKNOWLEDGEMENTS}

I would like to begin by thanking Dr. Tzvia Abramson for accepting me as her master's student and getting me interested in research. I never thought I would enjoy working in a lab, but thanks to her guidance and encouragement, I discovered how much I enjoyed research and what I was capable of accomplishing both in and out of the lab. I also want to say thank you to Dr. John Boothby and Dr. Ken Youngman for their advice and for reviewing and commenting on the manuscript. Additionally, thank you to the staff at San José State University, including Tim Andriese, Art Valencia, Marco Parent, and especially the veterinary staff, Larry Young and Nelia Medeiros, for their help and support.

This research project was the combined efforts of several people and I could not have done it without the constant help of Brian Kwong and Nicole Tarlton throughout the course of this project. Also thank you to Caroline Green for all her help and advice as well as all the students who helped with the experiments. I also want to say thank you to Linh Nguyen, Luis A. Zuniga, Jr., and Cecilia Oderup, who are our collaborators from Dr. Eugene Butcher's lab at Stanford University, for their advice and training. Also, thank you to Lusijah Rott for taking the time to train us to use the LSRII.

Finally, thank you to my brother Omar Waheed for proofreading my thesis, and last but not least, a big thank you to my parents, Khalid and Shamsunnisa Waheed, for always supporting me and encouraging me throughout my life and educational career. I could not have made it this far without you. 
TABLE OF CONTENTS

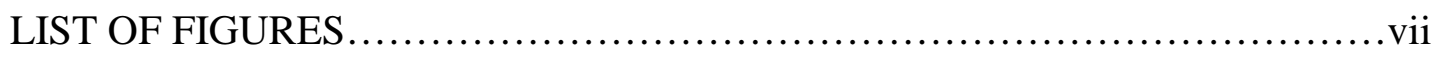

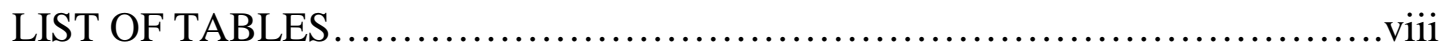

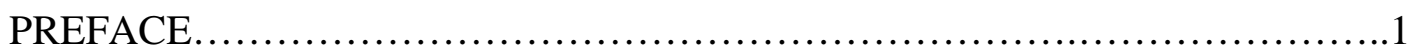

CHAPTER I

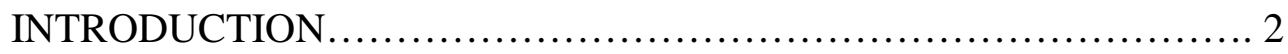

CHAPTER II

THE EFFECTS OF BORDETELLA PERTUSSIS ON DENDRITIC

CELL IMPRINTING OF CD4+ T CELLS.............................5

CHAPTER III

CONCLUSION ..................................................42

REFERENCES .......................................................45

APPENDICES

A. TIME COURSE EXPERIMENT TO DETERMINE PEAK

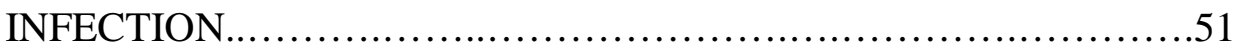

B. SUPPLEMENTARY DATA .....................................5 


\section{LIST OF FIGURES}

FIGURE 1. Experimental design....................................... 18

FIGURE 2. DC maturation 5 days post-infection with $B$. pertussis and $B$.

parapertussis........................................................20

FIGURE 3. Imprinting of trafficking molecules, 5 days post-infection, occurs

when DCs interact with CD4+ T cells...................................... 25

FIGURE 4. DC maturation 25 days post-infection with $B$. pertussis and

B. parapertussis..................................................... 28

FIGURE 5. The levels of trafficking molecules increase 25 days post-infection

in $B$. pertussis infection.................................................. 30

FIGURE 6. A time course of infection shows the peak infection days for

B. pertussis and B. parapertussis....................................... 51

FIGURE 7. DCs mature in response to $B$. pertussis infection even with smaller

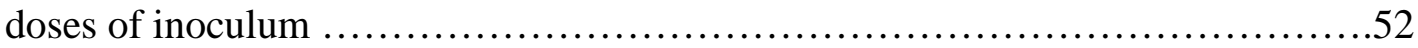

FIGURE 8. DCs mature in response to Bordetella and downregulation of homing molecules on CD4+ T cells was observed in B. pertussis co-cultures.............. 54

FIGURE 9. 25 days post-infection, the pattern of trafficking markers changes

compared to peak infection............................................58 


\section{LIST OF TABLES}

TABLE I. DC phenotypic markers......................................... 19

TABLE II. Trafficking markers and their functions............................24 


\section{PREFACE}

This thesis is comprised of three chapters and the appendices. Chapter I provides an overview of the research project and includes information regarding each part of the project. The second chapter is presented in journal format according to the guidelines set by the Journal of Immunology. The final chapter includes the conclusions from the research as well as a discussion of future directions. The appendices provide additional, supplementary data associated with this study. 


\section{CHAPTER I}

INTRODUCTION 


\section{Overview of the Research Project}

Immune cells such as lymphocytes circulate between the blood, lymph nodes, and organs due to chemotactic interactions between secreted and surface molecules in tissues and surface molecules on immune cells. This process is termed lymphocyte trafficking and is responsible for the recruitment of T lymphocytes to sites of infection (1). Lymphocyte trafficking (homing) to infected organs and tissues is crucial for the elimination of airborne pathogens and for restoration of a homeostatic environment such that unnecessary inflammation and tissue damage is prevented. T lymphocytes are able to home to specific organs due to a special combinatorial pattern of surface trafficking molecules that are "imprinted" on their surface during interaction with dendritic cells.

The trafficking molecules responsible for exclusive homing to the airways remain unknown. We report here our study of CD4+ T cell trafficking using two respiratory pathogens, B. pertussis, which produces pertussis toxin and, B. parapertussis, which does not. Pertussis toxin is responsible for lymphocytosis (extremely elevated levels of lymphocytes in the bloodstream) and is known to inhibit $\mathrm{G}$ proteins, which are responsible for cell signaling leading to chemotaxis or cell migration. Therefore we designed this study to observe the effects of pertussis toxin on dendritic cell imprinting of trafficking molecules on CD4+ T cells that could lead to preventing their exit from the bloodstream and entry into the lungs.

This project had two main objectives. The first objective was to analyze the presence of homing molecules on CD4+ T cells in three different compartments (lymph nodes, blood, and lungs), which was conducted primarily by Brian Kwong. Imprinting of 
homing molecules occurs in the lymph nodes so it was important to include the CD4+ T cell trafficking levels in our analyses. Levels of these molecules were also measured for CD4+ T cells in the blood and lungs to observe their phenotype after imprinting. Together the information from these tissues allowed us to compare the level of each trafficking marker in various compartments during experimental infection.

The second objective of this project was to mimic the in vivo imprinting process that takes place in the lymph nodes, and observe the resulting interactions that occur between isolated lung dendritic cells and naïve allogeneic splenocytes in an in vitro coculture system. The focus of this thesis was objective two of the overall research project, which should inform us about the effects of pertussis toxin on the ability of dendritic cells to imprint homing molecules on naïve $\mathrm{T}$ cells. To study this process, a co-culture system was developed using isolated lung dendritic cells from uninfected and Bordetella-infected mice and co-cultured overnight with naïve splenocytes to allow for imprinting. The expression levels of trafficking molecules on CD4+ T cells from uninfected and Bordetella-infected co-cultures were compared by flow cytometry. These experimental results will contribute to our understanding of the pathogenesis of B. pertussis, as well as the role of imprinting molecules in respiratory trafficking of $\mathrm{CD} 4+\mathrm{T}$ cells. This knowledge may lead to improved vaccine development targeting molecules that participate in lung homing. 
CHAPTER II

THE EFFECTS OF BORDETELLA PERTUSSIS ON DENDRITIC CELL IMPRINTING OF CD4+ T CELLS 
THE EFFECTS OF BORDETELLA PERTUSSIS ON DENDRITIC CELL IMPRINTING OF CD4+ T CELLS ${ }^{1}$

\author{
Sana Waheed, ${ }^{*}$ Tzvia Abramson, ${ }^{2} *$ \\ *Department of Biological Sciences, \\ San José State University, \\ San José, CA 95192
}

${ }^{1}$ This work was supported by funds from Dr. Tzvia Abramson and California State University Minigrant (2008).

${ }^{2}$ Address correspondence and reprint requests to Tzvia Abramson, Department of Biological Sciences, One Washington Square, San José State University, San José, CA 95192

Abbreviations used in this paper: DCs, dendritic cells; B. pertussis, Bordetella pertussis; B. parapertussis, Bordetella parapertussis; PTx, Pertussis Toxin; MHC, major histocompatibility complex; CD, cluster of differentiation; PBS, phosphate buffered saline; FCS, fetal calf serum; FSC, Forward Scatter; SSC, Side Scatter; PSGL-1, Pselectin glycoprotein ligand-1; VLA-1, very late antigen-1; LFA-1, lymphocyte functionassociated antigen-1; VLA-4, very late antigen-4; CCR5, chemokine receptor type 5; CCR6, chemokine receptor type 6; CXCR3, CXC chemokine receptor 3; VCAM-1, vascular cell adhesion molecule-1; CLA, cutaneous lymphocyte antigen. 


\begin{abstract}
Bordetella pertussis is an aerobic gram-negative bacterial pathogen that causes the human respiratory disease whooping cough. Despite widespread vaccination, whooping cough is reemerging due to decreased vaccine efficacy. One of the hallmarks of infection is lymphocytosis, which is induced by the pertussis toxin. Lymphocytes such as CD4+ T cells navigate to infected tissues through surface-trafficking molecules, which are imprinted during their interaction with tissue-associated dendritic cells. We hypothesized that the pertussis toxin affects the imprinting process resulting in altered expression of trafficking molecules on CD4+ T cells. We tested this hypothesis using a mouse model of infection. Imprinting levels on CD4+ T cells were compared to Bordetella parapertussis, a related strain that lacks pertussis toxin. Our results indicated that 5 days post-infection, the percentage of lung dendritic cells increased and adopted a mature phenotype (displaying an increased capability to migrate and present antigen to $\mathrm{T}$ cells) in response to $B$. pertussis infection, and there was an overall downregulation of trafficking molecules on CD4+ T cells. However, 25 days post-infection with $B$. pertussis, dendritic cells continued to express elevated levels of MHC class II, and the expression of trafficking markers on CD4+ T cells also increased compared to uninfected controls. These results enable identification of molecules that are specific for lymphocyte trafficking to the respiratory airways and contribute to knowledge useful in the development of better vaccines.
\end{abstract}




\section{Introduction}

Bordetella pertussis is an aerobic gram-negative bacterium that causes the respiratory disease whooping cough in humans. Considerable mortality was attributed to B. pertussis in the early twentieth century, which declined once a vaccine was introduced. However, whooping cough is reemerging in both adults and children due to drop in vaccine efficacy (2-3). Vaccinated adults can be carriers of pertussis and manifest a prolonged, but relatively mild respiratory disease, which may be transmitted to unvaccinated infants (4). In infants the manifestations can include vomiting, pneumonia, hypoxia, seizures or apnea. Throughout the world there are 300,000 pertussis-related deaths each year, mostly in children (5). Although these cases are mainly seen in developing areas of the world, there have been incidents of pertussis outbreaks in the United States and, according to the Centers for Disease Control and Prevention, the U.S. had over 10,000 reported cases of pertussis in 2007 (6). The onset of the disease is characterized by a persistent, forceful whoop-like cough that can last for several weeks to months, even after the clearance of the bacteria. The hallmark of the disease is leukocytosis with extreme lymphocytosis, which is attributed to one of the bacterial virulence factors, pertussis toxin (PTx) (7-10).

Bordetella pertussis is an extracellular pathogen that colonizes the upper respiratory system and bronchial epithelial cells. The respiratory system is constantly exposed to airborne antigens. The mucosal immunity maintains a steady state in which harmless antigens do not trigger unnecessary immune responses (11-12). Tissue resident DCs sample the airways and are key players in supporting immunological tolerance in 
response to non-pathogenic antigens (11). Bordetella pertussis overcomes this suppressive mechanism and disrupts these homeostatic conditions in the airways. Several bacterial factors contribute to the pathogenesis of B. pertussis in the respiratory tract. PTx is a secreted $A B$ subunit exotoxin that is associated with numerous pathogenic functions and immunomodulation. It is responsible for inhibiting chemotaxis in T cells, macrophages, neutrophils, and reduced B cell survival (13). The A subunit is the enzymatically active component that is responsible for ADP-ribosylation and inhibition of the alpha subunit of $\mathrm{G}$ proteins $(\mathrm{G} \alpha)$ on target host cells (14). G proteins are coupled to chemokine receptors and mediate cell signaling. PTx prevents activation of G $\alpha$ and interferes with signaling that leads to chemotaxis and cell migration $(8,15)$.

Administration of soluble PTx was reported to delay the initial recruitment of immune cells such as neutrophils and macrophages, which are responsible for engulfing and killing bacteria (16-20). Impaired neutrophil and macrophage function can lead to colonization of $B$. pertussis in the respiratory tract

During respiratory infection, DCs sample and pinocytose (internalize) antigen from the tracheal lumen and tissue-penetrating antigens. Immediately after antigen internalization, DCs develop a mature phenotype that is comprised of upregulation of surface maturation markers such as MHC class II, CD40, and CD86, which facilitate DC entry into the lymphatics and migration to the draining lymph nodes where antigen presentation to T cells occurs (21-23). The interaction of mature DCs with naïve $\mathrm{T}$ cells in the lymph nodes results in T cell activation, signaling, and upregulation of trafficking receptors, a mechanism called imprinting. Mature DCs derived from a specific tissue 
will then imprint $\mathrm{T}$ cells with trafficking receptors that direct them to the area of infection where the antigen was originally encountered by the DC (24).

Lymphocyte trafficking is a multi-step process that allows activated $\mathrm{T}$ cells to exit the lymph nodes, enter the bloodstream, extravasate, and home to infected tissue $(1,24-$ 26). The first step of this process is a rolling/tethering action mediated by selectins that loosely bind the $\mathrm{T}$ cell to inflamed endothelium and slows its transit in the bloodstream. This is followed by attachment and activation of the $\mathrm{T}$ cell by chemokine receptors. The third step is mediated by integrins, which completely halt the $\mathrm{T}$ cell in the bloodstream and mediate extravasation.

The concept of trafficking receptor imprinting on lymphocytes is well documented in the gut and skin where the trafficking molecules and environmental factors influencing this interaction have been identified (26). For example, DCs from gut origin imprint $\mathrm{T}$ cells in the presence of retinoic acid (a dietary environmental factor) with high levels of CCR9 and $\alpha 4 \beta 7$, which are the surface molecules that direct T cells to the small intestine $(1,25,27-30)$. Trafficking of $\mathrm{T}$ cells to the skin is mediated by DCs and activated Vitamin D3 derivatives that imprint CCR10, CLA, and CCR4, which leads $\mathrm{T}$ cells to the skin (1,31-33). As of now, the imprinting factors that direct $\mathrm{T}$ cell trafficking exclusively to the respiratory system have not been described (34).

In this thesis, we studied the interactions between DCs and T cells during a respiratory infection with $B$. pertussis. We hypothesized that $B$. pertussis (via PTx) alters DC imprinting of trafficking molecules on T cells. This may lead to a high degree of lymphocytosis in the circulation with reduced levels of trafficking molecules that can 
orient lymphocyte homing to the lungs. We tested our hypothesis using B. pertussis and Bordetella parapertussis experimental infections in mice. Bordetella parapertussis lacks PTx and was used as a control. This comparison elucidated the effects of PTx on G protein-coupled receptor signaling, as well as DC and T cell interactions leading to $\mathrm{T}$ cell homing (35-36). Since defective homing could lead to delayed clearance during $B$. pertussis infection, knowledge in this area should contribute to understanding the pathogenesis of this bacterium and aid in vaccine development based on lung associated trafficking molecules. 


\section{Materials and Methods}

All studies using animals have been approved by the Institutional Animal Care and Use Committee (IACUC) (Protocol \#921) at San José State University, San José, CA.

\section{Bacteria}

Two Bordetella strains were used, B. pertussis 338, which is a nalidixic acid-resistant derivative of the Tohama strain, and B. parapertussis, which was obtained from ATCC (\#9305). Both strains were grown on Bordet-Gengou blood plates, and single colonies were used to inoculate Stainer-Scholte broth containing Heptakis (Sigma-Aldrich, St. Louis, MO) prior to experimental infection.

\section{Experimental infection}

Six-week-old female Balb/c mice were inoculated intranasally with $20 \mu 1$ of $5 \times 10^{6}$ colony forming units of B. pertussis or B. parapertussis. Uninfected control mice received $20 \mu 1$ of PBS (37-38). Two time-points of experimental infection were established, 5 days post-infection (peak infection) and 25 days post-infection, which were determined by performing a time-course experiment where bacterial load in the lungs was measured for ten days and again on day 25 (see Appendix A). To confirm infection and determine the bacterial load, lungs from experimentally infected mice were harvested, homogenized, and plated on Bordet-Gengou plates prior to each experiment. 
Preparation of single cell suspensions from lungs and spleen

Mice were exsanguinated followed by perfusion of lungs with $30-50 \mathrm{ml}$ of PBS. The lungs and trachea were removed, minced and digested in RPMI-1640, 10\% FCS, 75U/ml DNase I (Sigma-Aldrich) and $250 \mathrm{U} / \mathrm{ml}$ Type I Collagenase (Worthington Biochemical Corporation, Lakewood, $\mathrm{NJ}$ ) in a $37^{\circ} \mathrm{C}$ orbital shaker for 45 to 60 minutes. The digested lungs were passed through a 40-micron nylon mesh strainer and cells were washed with RPMI-1640 to remove residual digest medium. Digested lung tissue was resuspended in 40\% Percoll (GE Lifescience, Piscataway, NJ), slowly underlaid with 70\% Percoll and centrifuged for 25 minutes to create a density gradient. Cells at the $40-70 \%$ interface (mononuclear cells) were collected and used for enrichment of DCs. The spleens from uninfected allogeneic mice were harvested and pressed through a nylon mesh to obtain a single cell suspension (39). Splenocytes were incubated with $3 \mathrm{ml}$ red blood cell lysis buffer (Sigma-Aldrich) for 5 minutes and washed with RPMI-1640 with 10\% FCS. Cell pellets from the lungs were resuspended in buffer (PBS, 0.5\% FCS, 2 mM EDTA) suitable for MACS columns.

Enrichment of lung DCs

All cell enrichments were performed using magnetic microbeads (Miltenyi Biotech, Auburn, CA). For DC enrichment from lungs, CD11c microbeads (N418) were used and lung mononuclear cells were enriched for CD11c+ cells using positive selection with a MiniMACS separator. Briefly, lung mononuclear cells were incubated with $100 \mu 1$ of CD11c microbeads for 15 minutes at $4^{\circ} \mathrm{C}$. Cells were washed with MACS buffer (PBS, 
$0.5 \%$ FCS, 2 mM EDTA) and resuspended in $500 \mu$ l of buffer. One MS column was used to enrich for CD11c+ cells.

\section{T cell activation and co-cultures}

For co-culturing experiments, 24-well plates were coated with the purified monoclonal antibodies CD3 $(1 \mu \mathrm{g} / \mathrm{ml})$ and CD28 $(1 \mu \mathrm{g} / \mathrm{ml})$ in PBS, and incubated at $4^{\circ} \mathrm{C}$, as adapted from Sigmundsdottir (33) and Campanelli (39). Enriched lung DCs were cultured with splenocytes from uninfected allogeneic mice at a 1:25 ratio in RPMI-1640 supplemented with $10 \%$ FCS, penicillin, streptomycin, IL-2 $(12.5 \mathrm{ng} / \mathrm{ml})$ and IL-12 $(2.5 \mathrm{ng} / \mathrm{ml})$ (R\&D Systems, Minneapolis, MN). Cells were co-cultured overnight at $37^{\circ} \mathrm{C}$ with $5 \% \mathrm{CO}_{2}$ to allow for imprinting, followed by flow cytometry analysis. T cell activation was determined using intracellular antibody staining with Ki-67 (B56) and interferon $\gamma$ (XMG1.2), which served as markers of $\mathrm{T}$ cell proliferation in an allogeneic system. Briefly, cells were stained for extracellular markers and resuspended in $250 \mu \mathrm{l}$ Fixation/Permeabilization (BD Biosciences, Franklin Lakes, NJ) solution and incubated at $4{ }^{\circ} \mathrm{C}$ for 20 minutes. Cells were washed twice with $1 \mathrm{ml}$ of $1 \times$ Perm/Wash Buffer (BD Biosciences) and then resuspended in $100 \mu \mathrm{l}$ of Perm/Wash Buffer containing the antibody or negative control. Cells were incubated at room temperature in the dark for 30 minutes before being washed twice with $1 \mathrm{ml} /$ wash of $1 \times$ Perm/Wash Buffer and resuspended in staining buffer (0.1\% Sodium Azide, $1 \%$ FCS, PBS). 


\section{Flow cytometry}

Analysis of surface and intracellular markers was done by flow cytometry. Lung derived DC phenotyping was measured by the expression of myeloid associated markers [CD11c (N418), CD11b (M1/70)] and maturation markers [MHC class II (M5/114.15.2), CD40

(3/23), CD86 (GL-1)]. Additional trafficking markers were evaluated on DCs as detailed for T cells. Expression of trafficking molecules on CD4+ T cells included CD4 (RM4-5, BD Biosciences and Invitrogen, Carlsbad, California), CD38 (90) and the following trafficking molecules: CD11a (M17/4), CD49f (GoH3), CD162 (2PH1, BD Biosciences), CXCR3 (220803, R\&D Systems), CD49a (HMalpha1, ABDSerotec, Raleigh, NC), CD49d (9C10 MFR4.B), and CD103 (2E7). All antibodies were purchased from BioLegend (San Diego, CA) unless otherwise indicated. The levels of these markers were compared for $B$. pertussis and B. parapertussis infections and normalized to uninfected controls as explained in the figure legends. Samples were acquired using the FACS Calibur (BD Biosciences) at San José State University and the LSRII (BD Biosciences) at Stanford University, and were analyzed using Flowjo. 


\section{Results}

\section{Experimental design}

Balb/c mice were inoculated intranasally with PBS (uninfected controls), $B$. pertussis or B. parapertussis for a period of 5 and 25 days. At each time-point lungs were harvested, mononuclear cells were obtained and enriched for DCs (CD11c+ cells) using Miltenyi Microbeads (Fig. 1). DCs were enumerated and phenotyped for each treatment using multicolor flow cytometry (Fig. 2, 4). Imprinting of trafficking molecules was observed in co-cultures of lung DCs with naïve allogeneic splenocytes from Swiss Webster mice (Fig. 3, 5).

\section{Peak infection: DCs matured in response to Bordetella infection}

Five days post-infection we found $23 \%$ of CD11c+ cells in uninfected control lungs, whereas B. parapertussis had $33.1 \%$ and B. pertussis had $70.6 \%$ (Fig. 2A). The percent DCs was estimated by the overall analysis of CD11c+ cells isolated from the lungs. DC phenotype was characterized using CD11c+ and a second marker (Table I) using flow cytometry (Fig. 2B). Levels of maturation markers were assessed with MHC class II, CD40, and CD86 (Fig C-D). These molecules bind to the T cell receptor, CD40L, and CD28 respectively on CD4+ T cells, forming an immunological synapse that results in T cell activation and stimulation (11). Since B. pertussis is an extracellular bacterial pathogen, we analyzed MHC class II, which is the molecule responsible for presenting antigen to CD4+ T cells. Lung DCs from uninfected mice revealed low levels of MHC class II, CD40, and CD86 (7.72\%, 10.64\%, 6.11\% respectively), whereas $B$. 
parapertussis-infected DCs showed increased expression (20.64\%, 13.67\%, 14.04\%). Comparatively, lung DCs from B. pertussis infection displayed the highest levels of maturation $(64.92 \%, 36.64 \%, 60.26 \%$ respectively).

The phenotypic marker CD11b is present on myeloid DCs of lung origin (40). Relatively low expression of CD11b (10.21\%) was observed in lung DCs from uninfected control mice while this percentage increased in B. parapertussis infection (20.5\%), but even more so in B. pertussis infection (61.04\%). Additionally, CCR5 was analyzed to observe DC migratory abilities to inflamed tissues. There was low expression of CCR5 in uninfected DCs (7.76\%) compared to B. parapertussis $(13.95 \%$,) and B. pertussis (55.84\%). Together, this data indicate that DCs mature during $B$. pertussis infection and do not appear to be inhibited by PTx. 


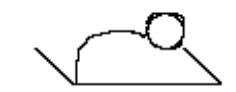

Uninfected (PBS)

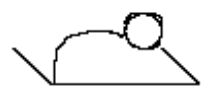

B. pertussis

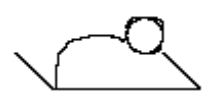

B. parapertussis
Infect Balb/c mice on Day 0

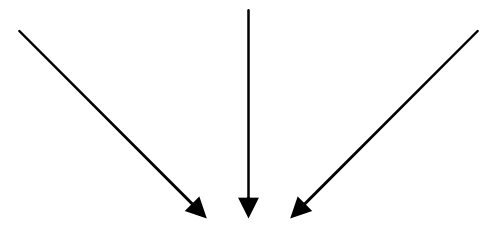

Time-points of 5 or 25 days post-infection

Harvest lungs and digest (separately)

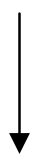

Obtain mononuclear cells with Percoll gradient

Enumerate DCs with multicolor flow cytometry
Enrich for DCs using CD11c microbeads

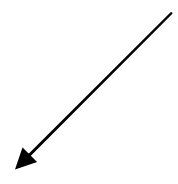

DC phenotyping using multicolor flow cytometry
Imprinting of trafficking molecules from co-culture of lung DCs with allogeneic splenocytes from Swiss Websters

FIGURE 1. Experimental design. Balb/c mice were infected and lungs were harvested 5 and 25 days post-infection. Lungs were processed and mononuclear cells were obtained to further enrich for CD11c+ cells. DCs were enumerated, phenotyped and analyzed for imprinting abilities in co-cultures with allogeneic splenocytes from Swiss Webster mice. 
TABLE I. DC phenotypic markers. The following markers were used to phenotype DCs and determine maturation levels for uninfected, $B$. pertussis and $B$. parapertussis infected lungs.

\begin{tabular}{|l|l|}
\hline Marker & Function \\
\hline CD11c & Expressed primarily on DCs \\
\hline CD40 & Co-stimulatory molecule \\
\hline CD86 & Co-stimulatory molecule \\
\hline MHC class II & Extracellular antigen presentation molecule \\
\hline CCR5 & Allows DC migration to inflamed tissue (24) \\
\hline CD11b & Integrin expressed on DCs and monocytes \\
\hline
\end{tabular}




\section{A Percent CD11c+ Cells per Treatment}

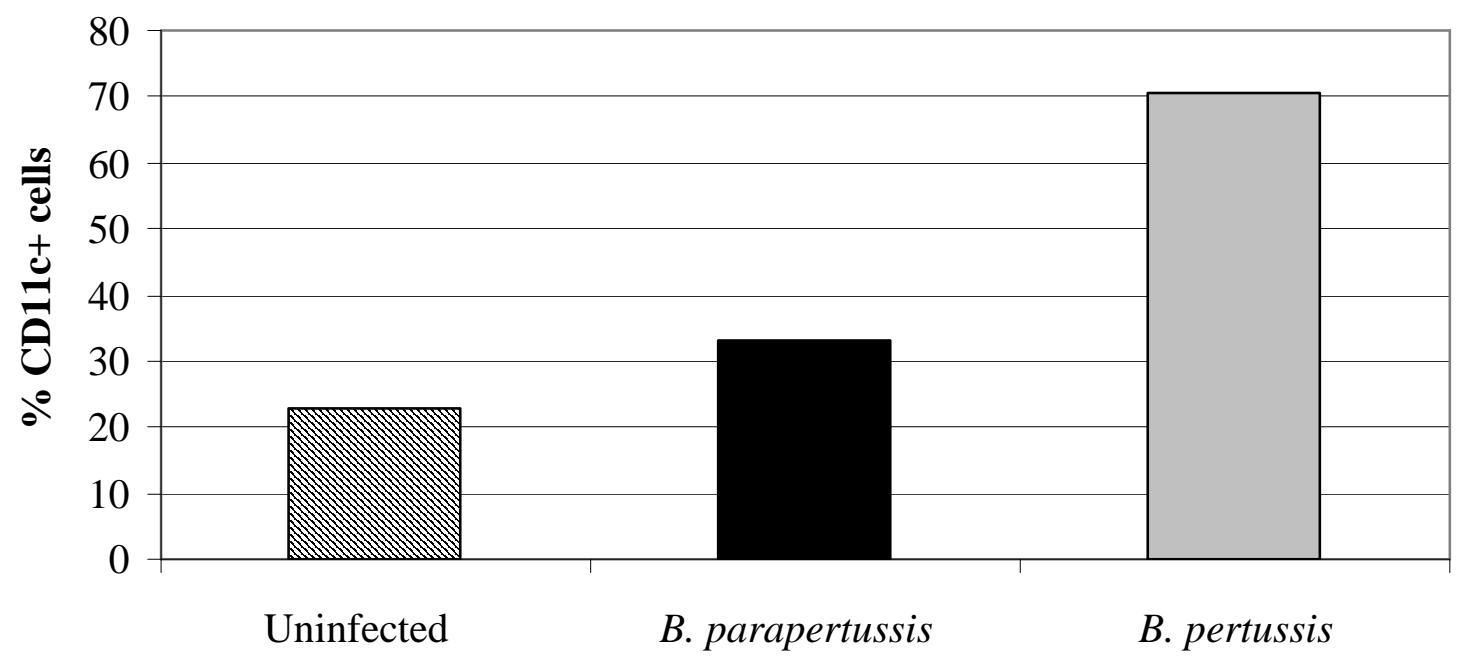

Treatment

2B

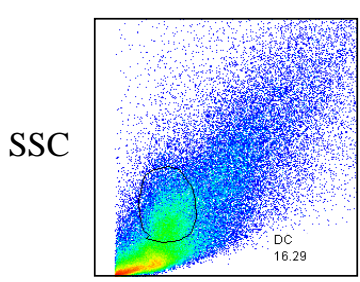

FSC
FSC-A

FSC-W

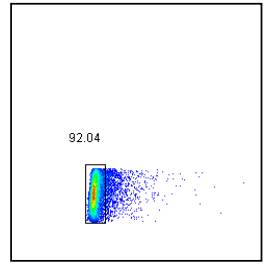

CD11c

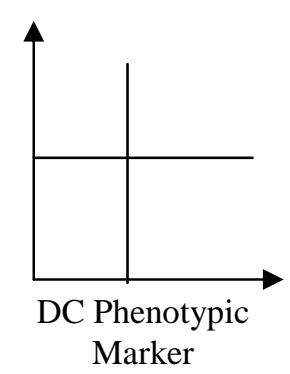

FIGURE 2. DC maturation 5 days post-infection with B. pertussis and B. parapertussis. Mononuclear cells were isolated from lungs and enriched for DCs. Percent of CD11c+ cells was estimated using quadrants that were placed according to positive controls $(A)$. Mononuclear cells were gated on monocytes, and doublets (cell clumping) were removed $(B)$. CD11c+ cells (DCs) were analyzed for a second phenotypic marker as detailed in $C$. (See Table I for a description of the markers). For DC maturation, we measured levels of CD40, CD86, MHC class II; myeloid associated marker CD11b, as well as ability to migrate to lymph nodes with CCR5 $(C-D)$. Data are representative of at least 4 independent experiments. 


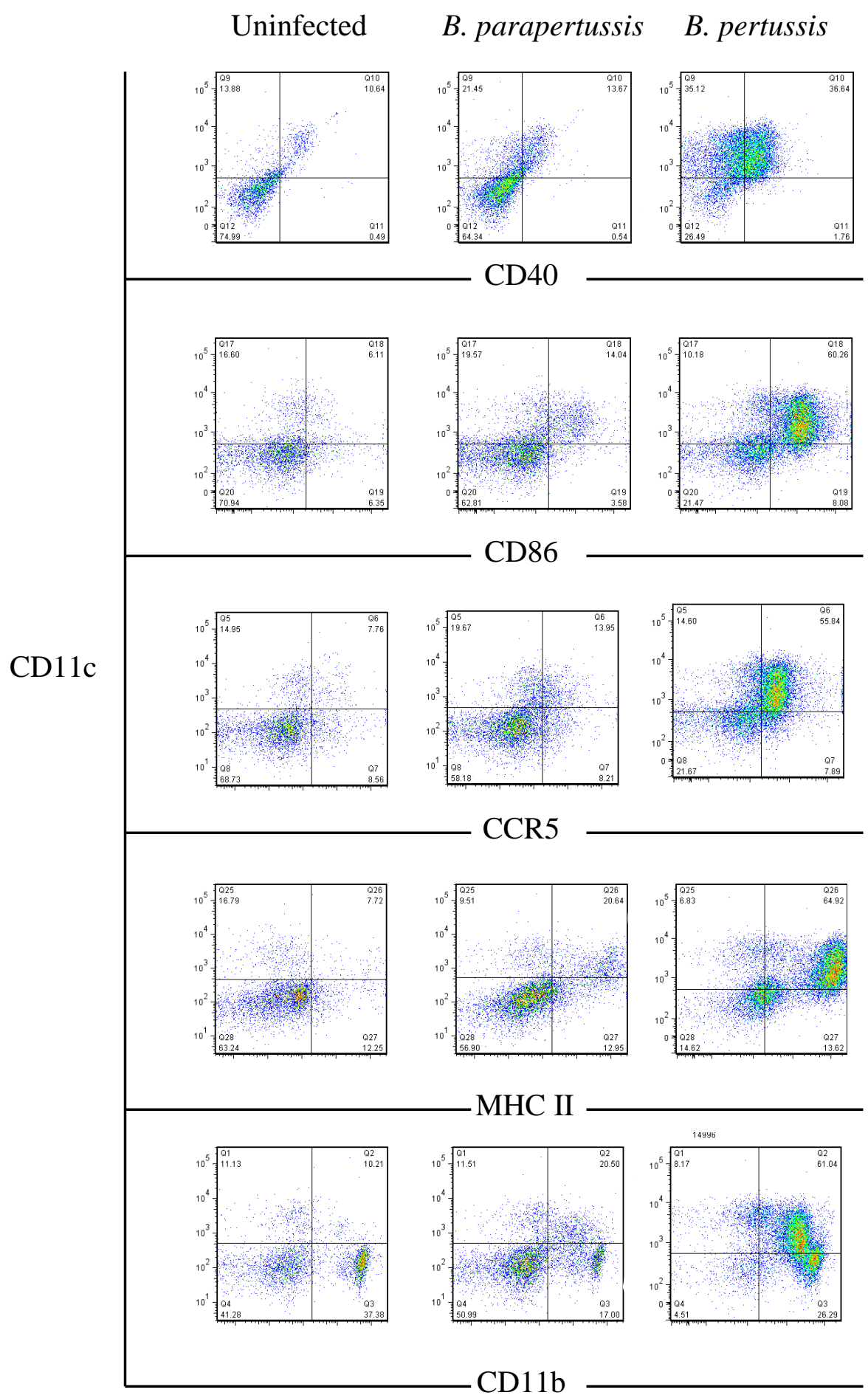




\section{D}

DC Phenotype 5 Days Post-Infection

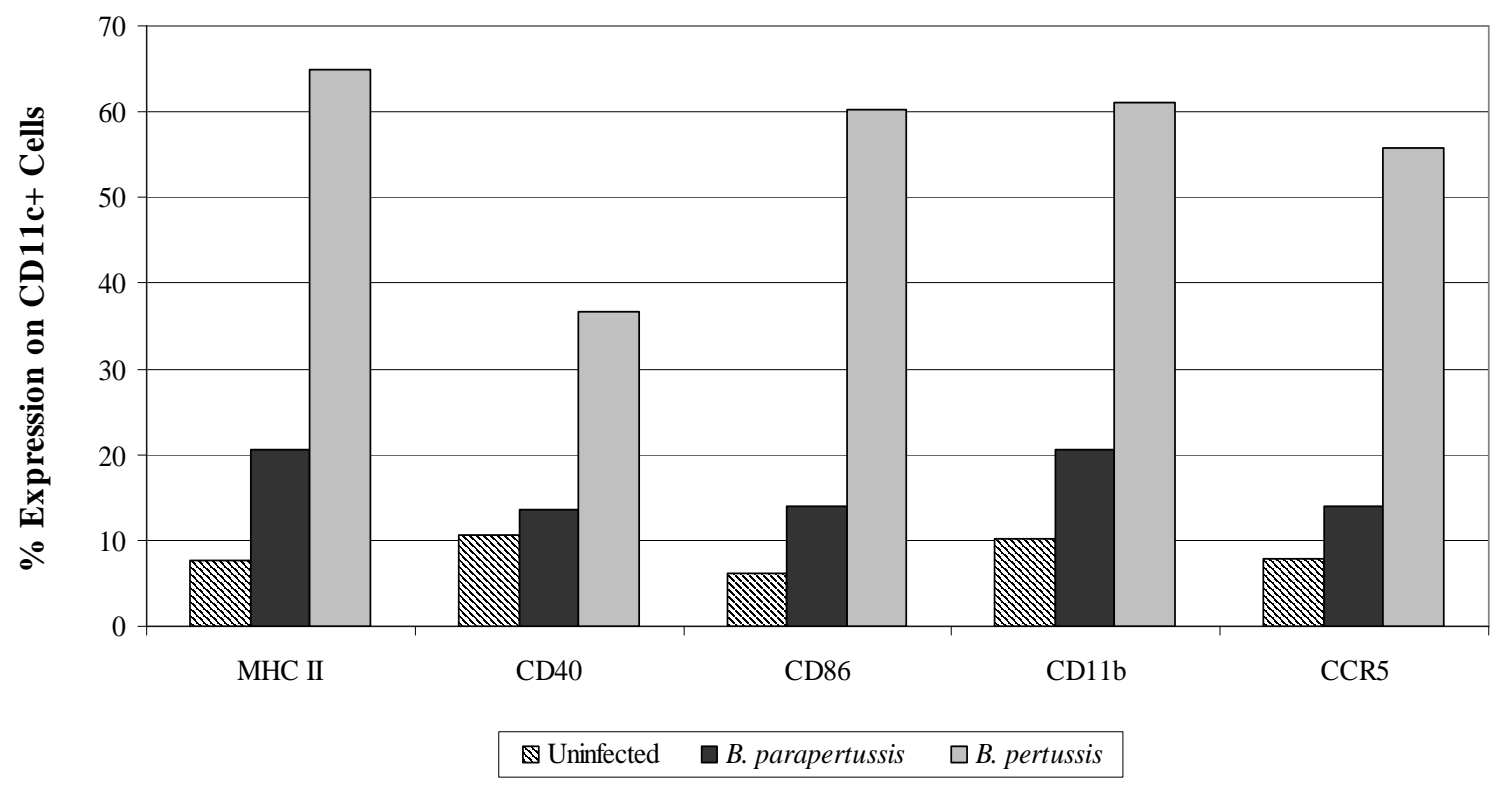

Infection with Bordetella alters trafficking receptor levels on nä̈ve CD4+T cells

In order to verify the imprinting ability of lung DCs derived from experimentally infected mice, we co-cultured lung DCs with naïve splenocytes from allogeneic mice. Establishing an allogeneic system ensures that imprinting occurs on proliferating $\mathrm{T}$ cells, where DCs interact through MHC class II with the T cell receptor and trigger nonspecific $\mathrm{T}$ cell proliferation. This leads to transcription of certain patterns of molecules that guide the $\mathrm{T}$ cell to the site of infection (33). These homing molecules are a combination of chemokine receptors and integrins that interact with inflamed endothelium and allow transmigration of the T cell from the bloodstream into the tissue. 
The proliferative nature of the allogeneic system was confirmed by intracellular staining for interferon $\gamma$ (secreted during T cell activation) and Ki-67 (a nuclear factor of proliferation) in activated CD38+ cells (Fig. 3A). A proliferating population was observed in each treatment; $0.5-1.8 \%$ of cells were positive for interferon $\gamma$ and roughly $2 \%$ were positive for Ki-67 indicating that we had a proliferating T cell system. DC ability to imprint trafficking markers on allogeneic $\mathrm{T}$ cells was then analyzed. Since little is known about specific lung homing markers, we analyzed a panel of trafficking molecules to determine whether the levels of imprinted homing molecules were altered in infected co-cultures compared to uninfected controls (Table 2). Our results indicate an overall downregulation of homing molecules on $\mathrm{CD} 4+\mathrm{T}$ cells during experimental $B$. pertussis infection compared to uninfected controls at 5 days post-infection. These results were normalized to uninfected control values set at $100 \%$.

Recent studies indicate that CD11a, CD162, and CD103 are important markers for trafficking and cell retention in the lungs $(28,41-45)$. On day 5 of infection, CD4+ T cells from B. parapertussis co-cultures showed upregulation of CD11a (125.9\%) and CD162 (114.9\%) but downregulation of CD103 (81.5\%) compared to uninfected controls (100\%) (Fig. 3C). In contrast B. pertussis co-cultures showed downregulation of CD11a (94.4\%) and CD162 (76.1\%) with upregulation of CD103 (130.3\%). Additionally, the integrins CD49a and CD49d can dimerize with CD29 and have been reported to migrate to the respiratory system $(21,46-47)$. However, downregulation was observed in both $B$. parapertussis and B. pertussis infections for CD49a (53.6\%, 75.6\% respectively) and CD49d (63.9\%, 81.9\% respectively) compared to uninfected controls (100\%). Another 
adhesion molecule, CD49f, may play a role in lung homing and was downregulated more in B. pertussis co-cultures $(69.9 \%)$ than in B. parapertussis $(89.6 \%)(27)$. There is also evidence in the literature that CXCR3 is involved in T cell homing to the lungs $(11,48$ 50). Five days post-infection with Bordetella, CXCR3 was downregulated in both $B$. parapertussis (49.6\%) and B. pertussis $(58.7 \%$,) compared to uninfected controls (100\%).

TABLE II. Trafficking markers and their functions. A variety of markers that are implicated in the homing process were analyzed, such as molecules involved in tethering or rolling and other integrins that mediate attachment to the endothelium and lead to extravasation.

\begin{tabular}{|l|l|l|}
\hline Marker & Function & Receptor Family \\
\hline CD162 (PSGL-1) & Adhesion (43) & Selectin \\
\hline CXCR3 & Chemotaxis of T cells (49) & Chemokine receptor \\
\hline CD11a (LFA-1) & Cell adhesion, costimulation (45) & Integrin \\
\hline CD49a $(\alpha 1)$ & Involved in T cell adhesion (46) & Integrin \\
\hline CD49d $(\alpha 4)$ & Cell migration, adhesion, homing (47) & Integrin \\
\hline CD49f $(\alpha 6)$ & Cell adhesion, migration (27) & Integrin \\
\hline CD103 $\left(\alpha_{\varepsilon}\right)$ & Tissue retention of lymphocytes (42) & Integrin \\
\hline CD38 & Activation marker & --- \\
\hline
\end{tabular}




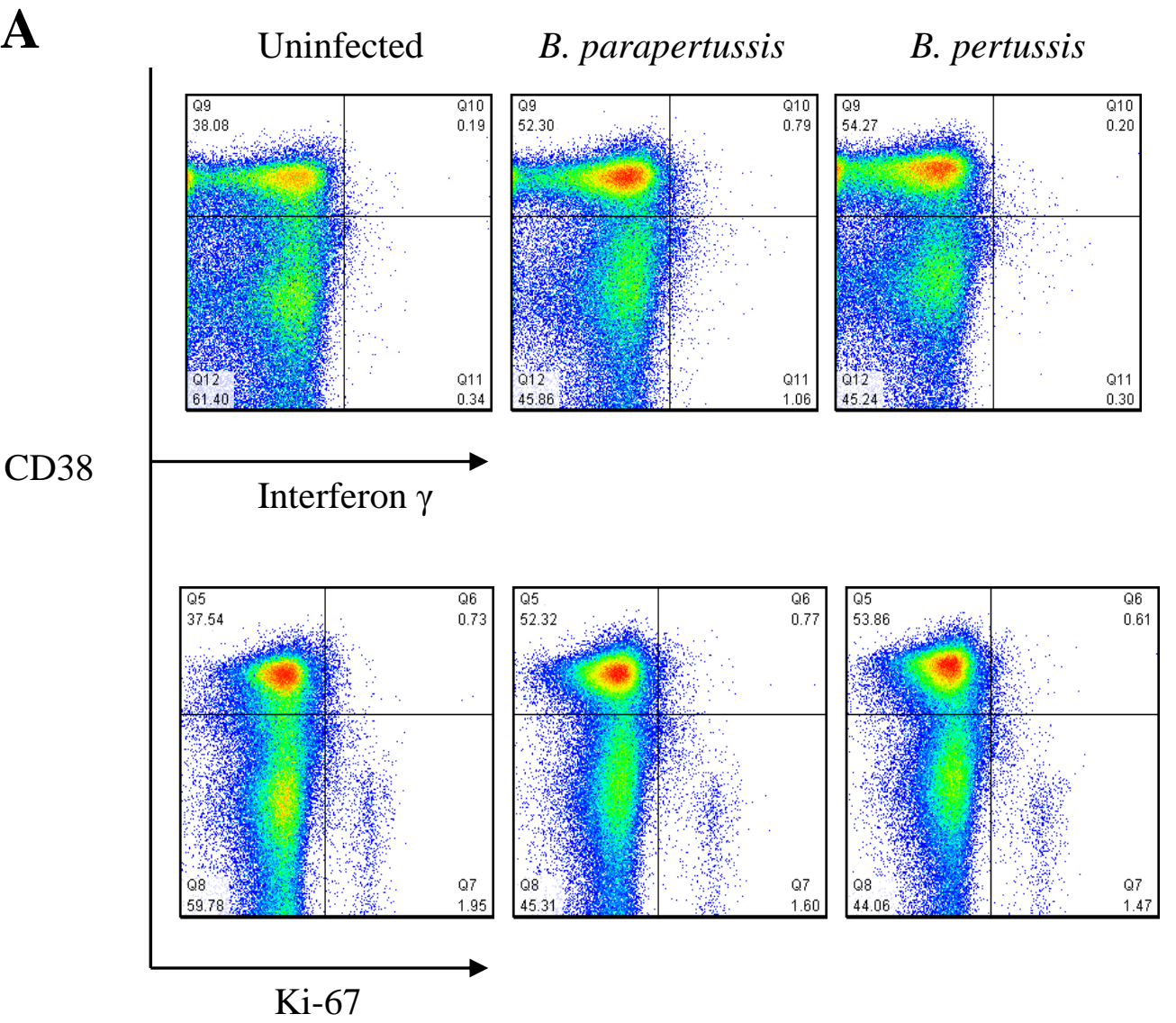

FIGURE 3. Imprinting of trafficking molecules, 5 days post-infection, occurs when DCs interact with CD4+ T cells. Lung DCs were cultured with naïve allogeneic splenocytes to allow for imprinting. Intracellular flow cytometry was used to confirm that co-cultures were an allogeneic system using CD38 with Ki-67 and interferon $\gamma(A)$. For co-culture experiments flow cytometry was used to gate on the lymphocytes, doublets (cell clumping) were removed and CD4+ cells were identified to determine the pattern of trafficking receptors $(B)$. In order to observe whether imprinting occurred, levels of the chemokine receptor CXCR3 and various integrins (CD11a, CD162, CD49f, CD49a, CD49d, and CD103) were measured $(C)$. (See Table II for a description of the markers). Data was normalized to uninfected controls (100\%) and are representative of at least 4 independent experiments. 


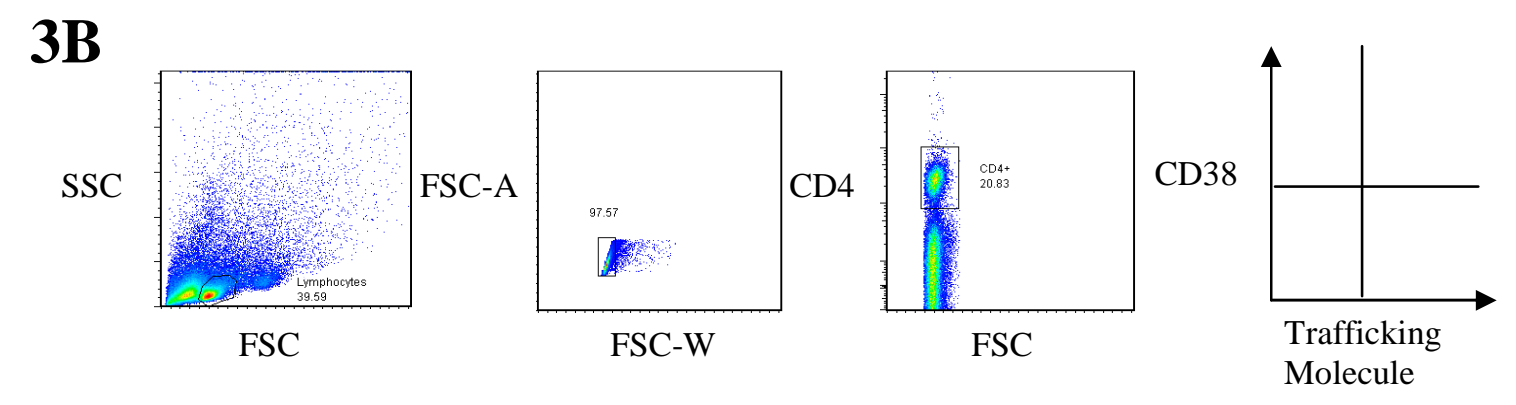

3C

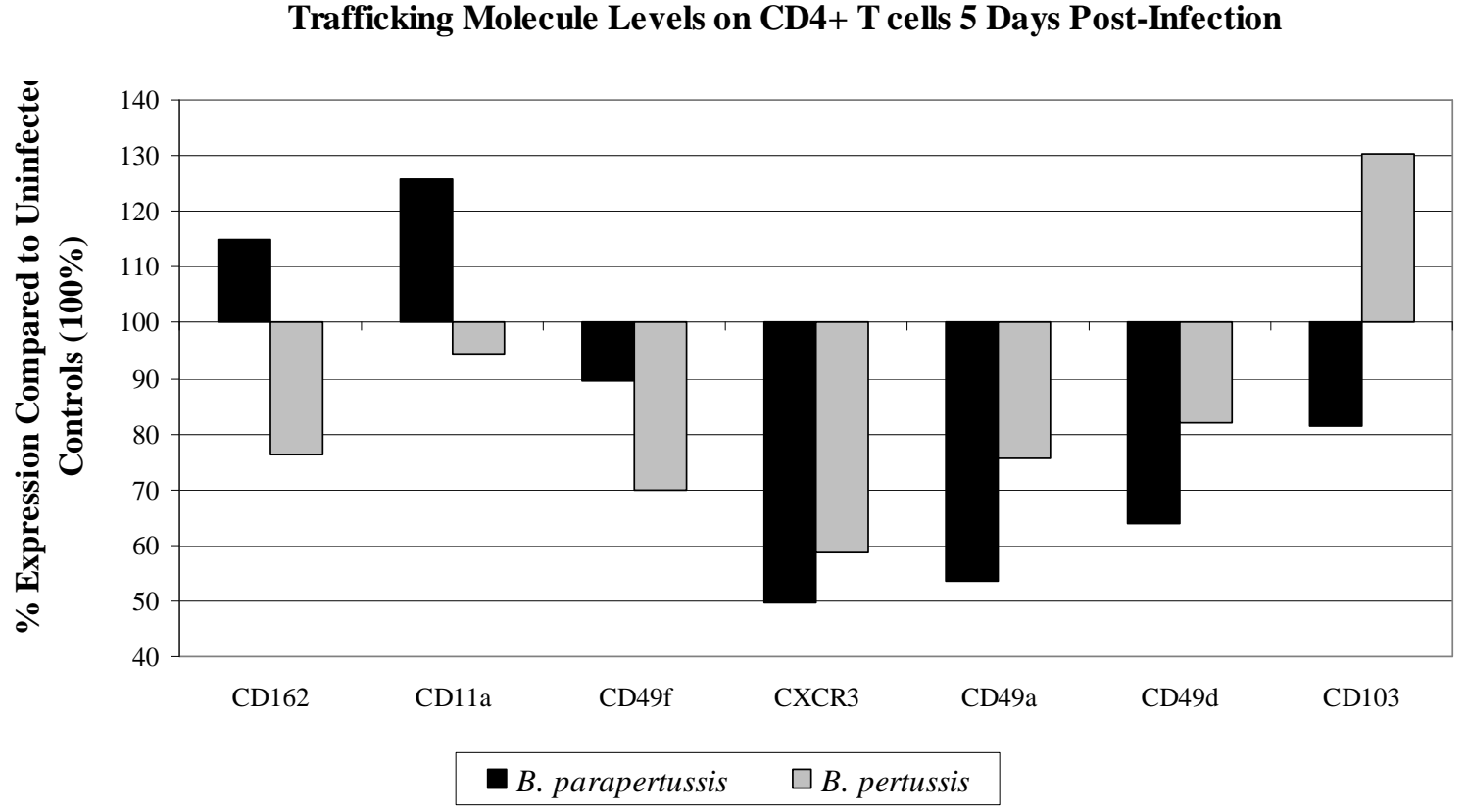


Twenty-five days post-infection: DC maturation levels decrease except for some markers in B. pertussis infection

In our previous experiment for 5 days post-infection, we observed an increase in both percent CD11c+ cells and DC maturation levels during experimental Bordetella infection. In order to establish the phenotypic state of DCs 25 days post-infection, lungs were harvested and lung mononuclear DCs were isolated. In the lungs, the percent gated CD11c+ cells decreased for B. pertussis (20.7\%) and B. parapertussis (23.1\%) infections to levels similar to uninfected controls (20.4\%) (Fig. 4A). DC phenotypic levels were then analyzed where lung DCs from B. parapertussis infection had reduced expression of the maturation marker CD86 (4.14\%) compared to B. pertussis (8.04\%) (Fig. 4B). In contrast, MHC class II remained upregulated in B. pertussis (18.3\%) whereas the levels for uninfected controls and B. parapertussis decreased to $6.74 \%$ and $7.57 \%$ respectively. The lung-associated marker CD11b was 5.24\% for lung DCs from uninfected controls, whereas DCs from B. pertussis infection had elevated levels (13.1\%) while DCs from B. parapertussis were downregulated (6.56\%). The DC migratory marker CCR5 was upregulated on DCs from B. pertussis (7.24\%) compared to B. parapertussis (3.59\%) and uninfected controls (3.75\%). Together, this indicates that the effect of Bordetella on DC phenotype diminished 25 days post-infection with the exception of B. pertussis infection where MHC class II, CD86, CD11b, and CCR5 remained elevated. 


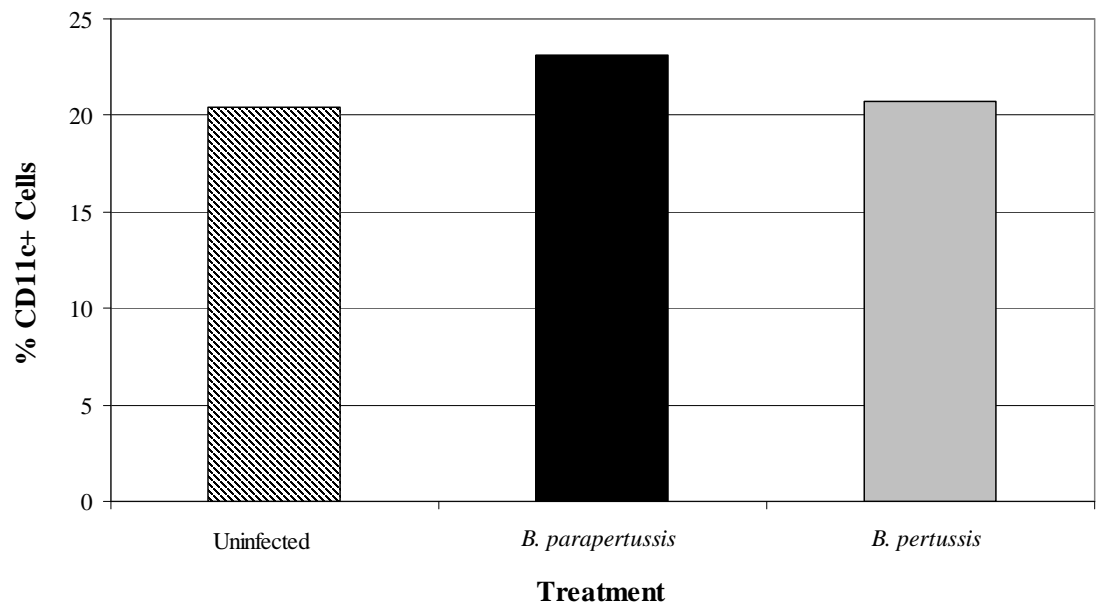

4B

DC Phenotype 25 Days Post-Infection

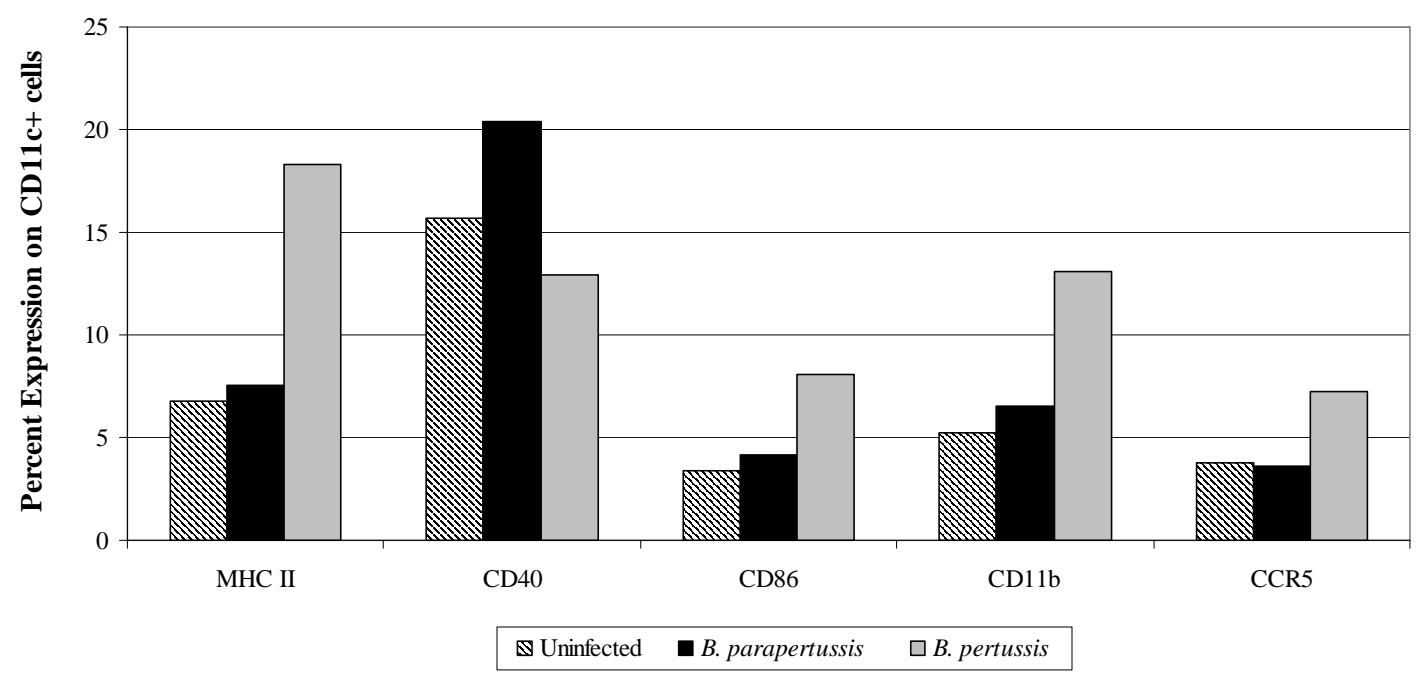

FIGURE 4. DC maturation 25 days post-infection with $B$. pertussis and $B$. parapertussis. After 25 days of infection lung mononuclear cells were obtained, enriched for DCs and gated similarly to that shown in Fig. 2B. We assessed the percent CD11c+ cells in each treatment (as determined using quadrants from flow cytometry dot plots) $(A)$ and evaluated DC maturation with MHC class II, CD40, CD86; myeloid and lung associated markers CD11b, CD11c, and migratory capability with CCR5 (B). Data are representative of at least 3 independent experiments. 
Trafficking receptor levels decreased in B. parapertussis co-cultures but increased in B. pertussis co-cultures 25 days after infection

Intracellular flow cytometry results of interferon $\gamma$ and Ki-67 confirmed the proliferative ability of each co-culture, as illustrated by the interferon $\gamma$ positive and $\mathrm{Ki}$ 67 positive populations (Fig. 5A). The level of trafficking receptors on CD4+ T cells was measured to determine whether DCs continued to actively imprint 25 days post-infection. In B. pertussis-infected co-cultures, the adhesion and lung retention marker CD11a was upregulated to $201.1 \%$ whereas it was downregulated in B. parapertussis-infected cocultures (113.5\%) when compared to uninfected controls (100\%) (Fig. 5B).

The integrins CD49d and CD49f are associated with migration and had reduced expression in B. parapertussis co-cultures (96.7\% and $95.1 \%$ respectively) when compared to B. pertussis co-cultures, which displayed elevated levels of CD49d (164.6\%) but maintained downregulation of CD49f (50.5\%). For B. pertussis co-cultures, CXCR3 remained downregulated (21.4\%) compared to uninfected controls (100\%). This suggests that 25 days post-infection, B. pertussis-infected DCs can imprint some trafficking molecules on $\mathrm{CD} 4+\mathrm{T}$ cells, while this is not the case for B. parapertussis-infected cocultures, where these molecules are expressed at low levels. 


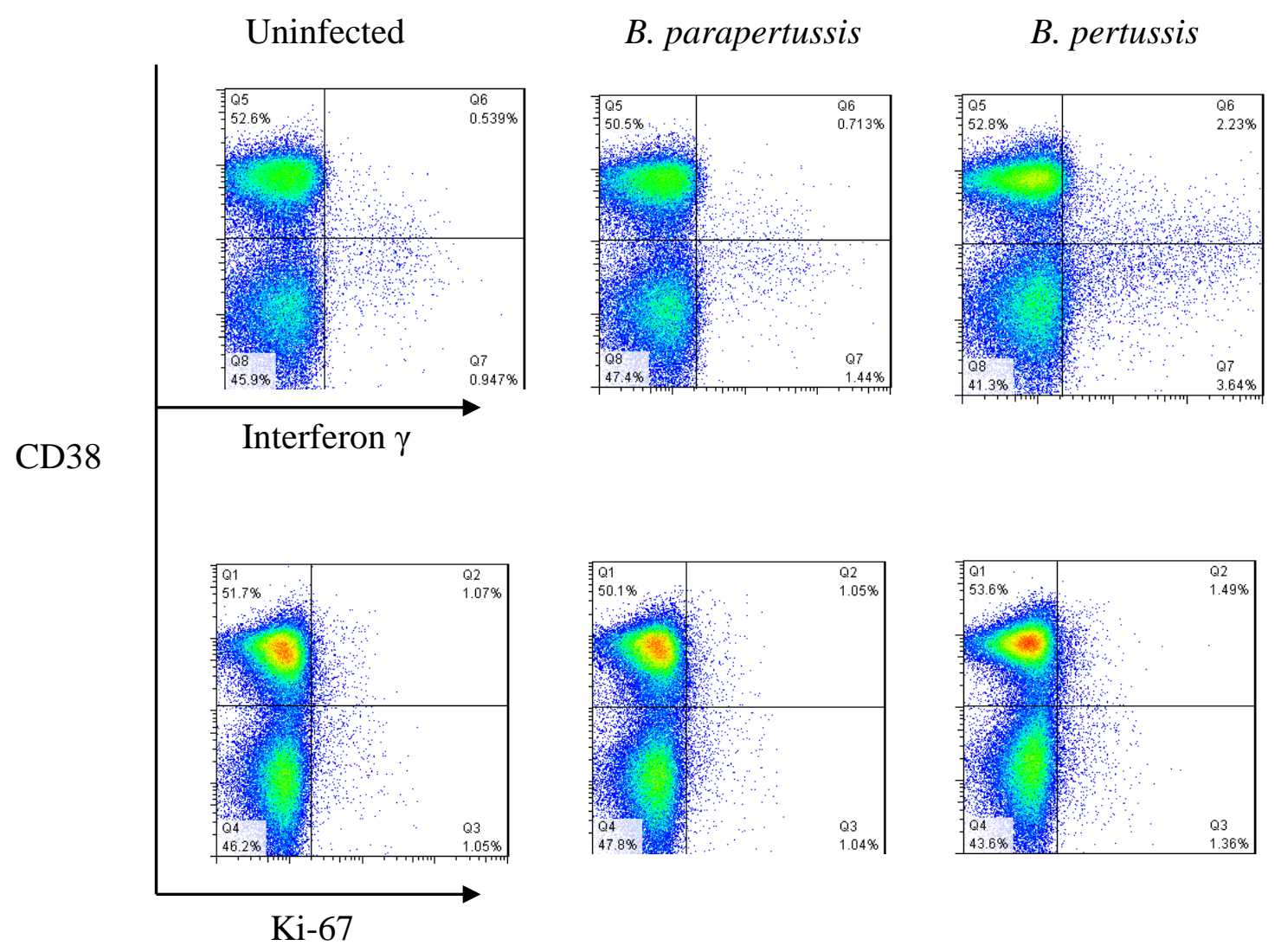

FIGURE 5. The levels of trafficking molecules increase 25 days post-infection in $B$. pertussis infection. Lung DCs were cultured with naïve splenocytes overnight to allow for imprinting. Intracellular staining with interferon $\gamma$ and Ki-67 was included to confirm that imprinting occurred in the allogeneic co-cultures $(A)$. To determine the levels of imprinted markers, we gated on the lymphocytes, removed doublets (cell clumping), and identified trafficking markers on CD4+ cells (gating similar to that shown in Fig. 3B). On day 25 of infection we measured levels of lung retention molecules (CD11a, CD162, CD103), integrins (CD49a, CD49d, CD49f), and the chemokine receptor CXCR3 (B). All values were normalized to uninfected controls (100\%). Data are representative of at least 3 independent experiments. 


\section{B}

Trafficking Molecule Levels on CD4+ T cells 25 Days Post-Infection

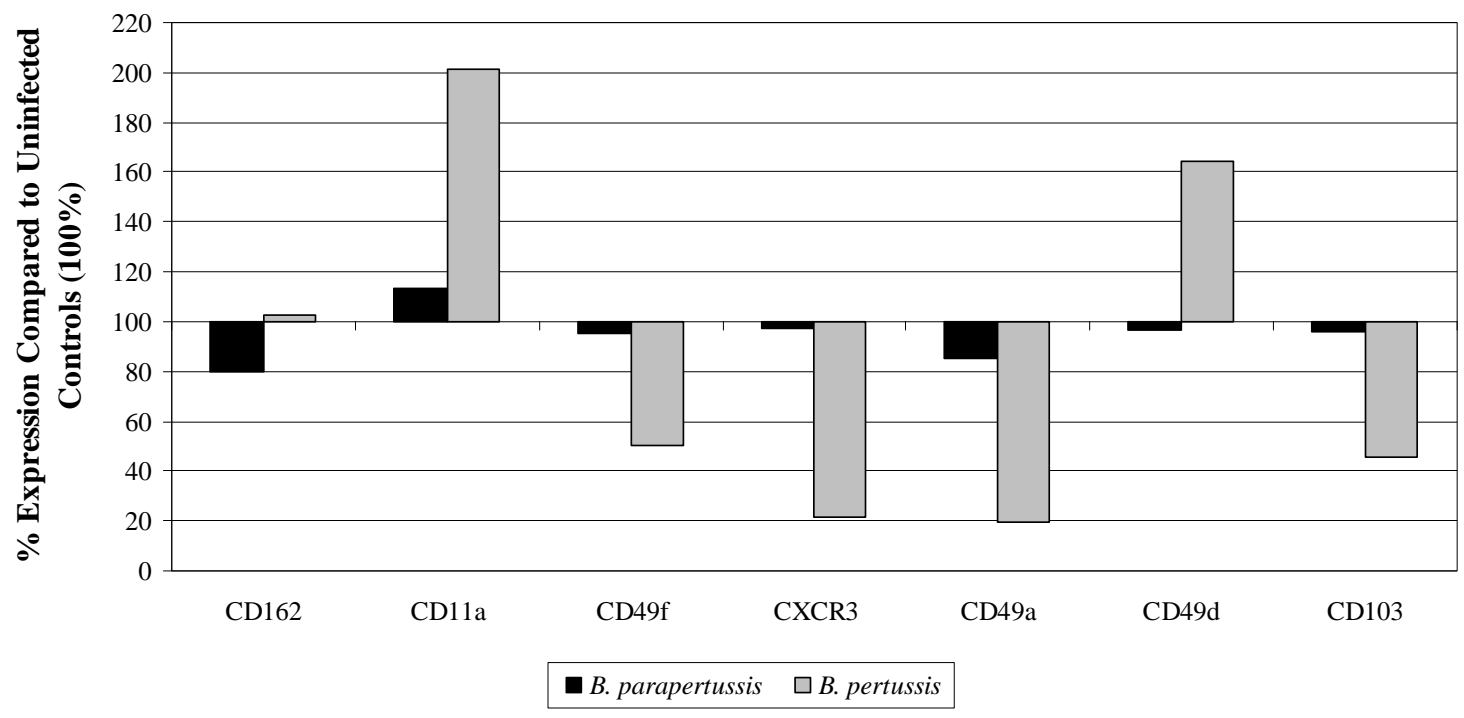




\section{Discussion}

Unlike other areas of the body such as the skin and gut where specific homing molecules that govern lymphocyte trafficking have been established (26), a unique trafficking molecule pattern to the respiratory airways remains to be defined. We were interested in elucidating the role PTx has on DC imprinting of trafficking molecules on CD4+ T cells that guides them to the respiratory system. PTx inhibits G protein activation and hinders chemotaxis of cells $(8,13,15)$. Therefore, we established an experimental respiratory infection model using two bacteria from the Bordetella species: B. pertussis (produces PTx) and B. parapertussis (lacks PTx).

DC origin and their level of maturation are critical components for imprinting. Therefore, we utilized flow cytometry to determine DC phenotype for uninfected controls and Bordetella-infected DCs. At 5 days post-infection, CD11c+ cells increased 1.4 times in B. parapertussis infection, whereas there was a 3-fold increase in B. pertussis infection compared to uninfected controls. This increase in CD11c+ cells may either be due to recruitment of DCs in the lungs during a state of infection or inability to leave the lungs and migrate to the lymph nodes, a phenomenon that could be attributed to PTx inhibition of chemokine receptors such as CCR7. However, by 25 days post-infection, the percent CD11c+ cells in the lungs decreased for both infections, possibly due to a halt in recruitment of these cells to the lungs.

In contrast to those who report partial DC maturation during $B$. pertussis infection (51), our results indicated that 5 days post-infection, lung DCs from $B$. pertussis infection had upregulated MHC class II, CD40 and CD86 and had generally higher levels of 
maturation compared to that in B. parapertussis infection or uninfected controls. This discrepancy between our results and those of others may be attributed to the timing of post-infection sampling or differences in bacterial strains. The phenotype of DCs changed 25 days post-infection for $B$. parapertussis so that MHC class II, CD86, CD11b, and CCR5 were downregulated compared to B. pertussis. However MHC class II remained upregulated in $B$. pertussis, which may be due to continued antigen presentation to CD4+ T cells in the regional lymph nodes even at late stages of infection. Together this information indicated that 5 days post-infection, $B$. pertussis does not prevent DCs from acquiring a mature phenotype that is required for imprinting CD4+ T cells. However, by 25 days after infection, $B$. parapertussis-infected lungs appeared to revert to steady-state conditions, which may not be the case for $B$. pertussis infection. An important chemokine receptor, CCR7, is required for entry into lymph nodes (24). In order to further characterize the migratory ability of B. pertussis-infected DCs, CCR7 assessment will be included in future experiments.

Once the DC phenotype was established, isolated lung DCs were co-cultured with naïve splenocytes harvested from allogeneic mice, and imprinting of trafficking molecules on CD4+ T cells was analyzed. CD11a and CD162 have been reported to be important for adhesion and retention of cells in the lungs $(43,45)$. Interestingly, we found that on day 5 post-infection, both CD11a and CD162 were downregulated in $B$. pertussis infection but upregulated in B. parapertussis, which suggests that PTx has a role in suppressing these molecules during peak infection. However, on day 25 post- 
infection, CD11a levels were elevated, suggesting that this marker is upregulated only at later stages of infection, perhaps after the effects of PTx have diminished.

Bordetella pertussis also showed elevated levels of CD103 on day 5 postinfection, while it was downregulated in B. parapertussis co-cultures. CD103 has been shown to be involved in tissue retention of lymphocytes (42), and perhaps CD4+ T cells are retained in the tissue instead of migrating during $B$. pertussis infection. There is also evidence that CXCR3 is important for CD4+ T cell recruitment to the airways (11) and both Bordetella infections showed decreased levels of CXCR3 on day 5 of infection, while $B$. pertussis infection continued to show downregulation on day 25 . This indicates that perhaps both species prevent initial T cell recruitment to the lung through this chemokine receptor.

The results from this research project suggest that $B$. pertussis downregulates certain trafficking molecules during peak infection; however, at later stages of infection these molecules are upregulated. Since B. pertussis is a prolonged respiratory disease, it is possible that imprinting of trafficking molecules on $\mathrm{CD} 4+\mathrm{T}$ cells persists during later stages of infection, perhaps due to the decreased effects of PTx. Our experiments indicate that the lung environment for $B$. parapertussis returned to a state of homeostasis 25 days after infection, whereas this is not the case for $B$. pertussis infection.

Further studies can also include additional trafficking molecules such as CLA, CCR9 and $\alpha 4 \beta 7$ due to their presence on T cells that traffic exclusively to the skin and gut respectively. Therefore, low levels of these molecules may be observed on T cells that home to the respiratory system $(30,48,52)$. Additional experiments may include in 
vitro infection of uninfected lung DCs pulsed with PTx, to assess the antigen specific response and imprinting of trafficking molecules that are PTx-dependent. Antigen pulsed DCs could be co-cultured with naïve splenocytes to allow for imprinting, and results can be compared to in vivo experimental Bordetella infection. In order to further confirm the role of PTx, an experimental infection with B. parapertussis complemented with soluble PTx could be included and compared to B. pertussis (18). This information will increase our understanding of the pathogenesis of B. pertussis, and the role of PTx in preventing lymphocyte recruitment to the respiratory system through trafficking molecule modulation. This line of research may identify the molecules responsible for the exclusive recruitment of $\mathrm{CD} 4+\mathrm{T}$ cells to the airways, leading to a more efficacious vaccine design that targets trafficking molecules important in B. pertussis infection. 


\section{References}

1. Butcher EC, Picker LJ. 1996. Lymphocyte homing and homeostasis. Science 272: 606.

2. Carbonetti NH. 2007. Immunomodulation in the pathogenesis of Bordetella pertussis infection and disease. Curr Opin Pharmacol 7: 272-8.

3. McIntyre P, Wood N. 2009. Pertussis in early infancy: disease burden and preventive strategies. Curr Opin Infect Dis 22: 215-23.

4. Mattoo S, Cherry JD. 2005. Molecular pathogenesis, epidemiology, and clinical manifestations of respiratory infections due to Bordetella pertussis and other Bordetella subspecies. Clin Microbiol Rev 18: 326-82.

5. Crowcroft NS, Pebody RG. 2006. Recent developments in pertussis. Lancet 367: 1926-36.

6. Pertussis. Department of Health and Human Services. 2009. Centers for Disease Control and Prevention. 19 Feb 2010. <http://www.cdc.gov/ncidod/dbmd/Diseaseinfo/pertussis_t.htm>.

7. Bernales R, Eastman J, Kaplan J. 1976. Quantitation of circulating T and B lymphocytes in children with whooping cough. Pediatr Res 10: 965-7.

8. Mooi FR. 1988. Virulence factors of Bordetella pertussis. Antonie Van Leeuwenhoek 54: 465-74.

9. Munoz JJ, Arai H, Bergman RK, Sadowski PL. 1981. Biological activities of crystalline pertussigen from Bordetella pertussis. Infect Immun 33: 820-6.

10. Pittman M. 1979. Pertussis toxin: the cause of the harmful effects and prolonged immunity of whooping cough. A hypothesis. Rev Infect Dis 1: 401-12. 
11. Kohlmeier JE, Woodland DL. 2009. Immunity to respiratory viruses. Annu Rev Immunol 27: 61-82.

12. Weiner HL. 2004. Tolerogenic dendritic cells and T regulatory cells in the mucosa. Sociedade Brasileira de Imunologia. 24 Mar 2009 <http://www.sbi.org.br/sbinarede/SBInarede25/howard.htm>.

13. Mills KH. 2001. Immunity to Bordetella pertussis. Microbes Infect 3: 655-77.

14. Smith AM, Guzman CA, Walker MJ. 2001. The virulence factors of Bordetella pertussis: a matter of control. FEMS Microbiol Rev 25: 309-33.

15. Aepfelbacher M, Aktories K, Just I. 2000. Bacterial protein toxins. Berlin ; New York: Springer. xxxii, p. 167-185.

16. Andreasen C, Carbonetti NH. 2008. Pertussis toxin inhibits early chemokine production to delay neutrophil recruitment in response to Bordetella pertussis respiratory tract infection in mice. Infect Immun 76: 5139-48.

17. Carbonetti NH, Artamonova GV, Andreasen C, Bushar N. 2005. Pertussis toxin and adenylate cyclase toxin provide a one-two punch for establishment of Bordetella pertussis infection of the respiratory tract. Infect Immun 73: 2698-703.

18. Carbonetti NH, Artamonova GV, Mays RM, Worthington ZE. 2003. Pertussis toxin plays an early role in respiratory tract colonization by Bordetella pertussis. Infect Immun 71: 6358-66.

19. Kirimanjeswara GS, Agosto LM, Kennett MJ, Bjornstad ON, Harvill ET. 2005. Pertussis toxin inhibits neutrophil recruitment to delay antibody-mediated clearance of Bordetella pertussis. J Clin Invest 115: 3594-601.

20. Meade BD, Kind PD, Ewell JB, McGrath PP, Manclark CR. 1984. In vitro inhibition of murine macrophage migration by Bordetella pertussis lymphocytosis-promoting factor. Infect Immun 45: 718-25. 
21. Holt PG, Strickland DH, Wikstrom ME, Jahnsen FL. 2008. Regulation of immunological homeostasis in the respiratory tract. Nat Rev Immunol 8: 142-52.

22. Jahnsen FL, Strickland DH, Thomas JA, Tobagus IT, Napoli S, Zosky GR, Turner DJ, Sly PD, Stumbles PA, Holt PG. 2006. Accelerated antigen sampling and transport by airway mucosal dendritic cells following inhalation of a bacterial stimulus. $J$ Immunol 177: 5861-7.

23. Kim CH, Campbell DJ, Butcher EC. 2001. Nonpolarized memory T cells. Trends Immunol 22: 527-30.

24. Sallusto F, Mackay CR, Lanzavecchia A. 2000. The role of chemokine receptors in primary, effector, and memory immune responses. Апnи Rev Immunol 18: 593-620.

25. Mora JR. 2008. Homing imprinting and immunomodulation in the gut: role of dendritic cells and retinoids. Inflamm Bowel Dis 14: 275-89.

26. Sigmundsdottir H, Butcher EC. 2008. Environmental cues, dendritic cells and the programming of tissue-selective lymphocyte trafficking. Nat Immunol 9: 981-7.

27. Abitorabi MA, Mackay CR, Jerome EH, Osorio O, Butcher EC, Erle DJ. 1996. Differential expression of homing molecules on recirculating lymphocytes from sheep gut, peripheral, and lung lymph. J Immunol 156: 3111-7.

28. Butcher EC, Williams M, Youngman K, Rott L, Briskin M. 1999. Lymphocyte trafficking and regional immunity. Adv Immunol 72: 209-53.

29. Iwata M, Hirakiyama A, Eshima Y, Kagechika H, Kato C, Song SY. 2004. Retinoic acid imprints gut-homing specificity on T cells. Immunity 21: 527-38.

30. Kunkel EJ, Campbell JJ, Haraldsen G, Pan J, Boisvert J, Roberts AI, Ebert EC, Vierra MA, Goodman SB, Genovese MC, Wardlaw AJ, Greenberg HB, Parker CM, Butcher EC, Andrew DP, Agace WW. 2000. Lymphocyte CC chemokine receptor 9 and epithelial thymus-expressed chemokine (TECK) expression distinguish the small 
intestinal immune compartment: Epithelial expression of tissue-specific chemokines as an organizing principle in regional immunity. J Exp Med 192: 761-8.

31. Campbell JJ, Haraldsen G, Pan J, Rottman J, Qin S, Ponath P, Andrew DP, Warnke R, Ruffing N, Kassam N, Wu L, Butcher EC. 1999. The chemokine receptor CCR4 in vascular recognition by cutaneous but not intestinal memory T cells. Nature 400: 776-80.

32. Reiss Y, Proudfoot AE, Power CA, Campbell JJ, Butcher EC. 2001. CC chemokine receptor (CCR)4 and the CCR10 ligand cutaneous T cell-attracting chemokine (CTACK) in lymphocyte trafficking to inflamed skin. J Exp Med 194: 1541-7.

33. Sigmundsdottir H, Pan J, Debes GF, Alt C, Habtezion A, Soler D, Butcher EC. 2007. DCs metabolize sunlight-induced vitamin D3 to 'program' T cell attraction to the epidermal chemokine CCL27. Nat Immunol 8: 285-93.

34. de Bree GJ, van Leeuwen EM, Out TA, Jansen HM, Jonkers RE, van Lier RA. 2005. Selective accumulation of differentiated CD8+ T cells specific for respiratory viruses in the human lung. J Exp Med 202: 1433-42.

35. Arico B, Gross R, Smida J, Rappuoli R. 1987. Evolutionary relationships in the genus Bordetella. Mol Microbiol 1: 301-8.

36. Arico B, Rappuoli R. 1987. Bordetella parapertussis and Bordetella bronchiseptica contain transcriptionally silent pertussis toxin genes. J Bacteriol 169: 2847-53.

37. Wolfe DN, Kirimanjeswara GS, Harvill ET. 2005. Clearance of Bordetella parapertussis from the lower respiratory tract requires humoral and cellular immunity. Infect Immun 73: 6508-13.

38. Zachariadis O, Cassidy JP, Brady J, Mahon BP. 2006. Gammadelta T cells regulate the early inflammatory response to Bordetella pertussis infection in the murine respiratory tract. Infect Immun 74: 1837-45. 
39. Campanelli AP, Roselino AM, Cavassani KA, Pereira MS, Mortara RA, Brodskyn CI, Goncalves HS, Belkaid Y, Barral-Netto M, Barral A, Silva JS. 2006.

CD4+CD25+ T cells in skin lesions of patients with cutaneous leishmaniasis exhibit phenotypic and functional characteristics of natural regulatory T cells. J Infect Dis 193: 1313-22.

40. Gonzalez-Juarrero M, Shim TS, Kipnis A, Junqueira-Kipnis AP, Orme IM. 2003. Dynamics of macrophage cell populations during murine pulmonary tuberculosis. $J$ Immunol 171: 3128-35.

41. Dunne PJ, Moran B, Cummins RC, Mills KH. 2009. CD11c+CD8alpha+ dendritic cells promote protective immunity to respiratory infection with Bordetella pertussis. $J$ Immunol 183: 400-10.

42. Suffia I, Reckling SK, Salay G, Belkaid Y. 2005. A role for CD103 in the retention of CD4+CD25+ Treg and control of Leishmania major infection. J Immunol 174: 544455.

43. Clark JG, Mandac-Dy JB, Dixon AE, Madtes DK, Burkhart KM, Harlan JM, Bullard DC. 2004. Trafficking of Th1 cells to lung: a role for selectins and a P-selectin glycoprotein-1-independent ligand. Am J Respir Cell Mol Biol 30: 220-7.

44. Ghosh S, Chackerian AA, Parker CM, Ballantyne CM, Behar SM. 2006. The LFA-1 adhesion molecule is required for protective immunity during pulmonary Mycobacterium tuberculosis infection. J Immunol 176: 4914-22.

45. Thatte J, Dabak V, Williams MB, Braciale TJ, Ley K. 2003. LFA-1 is required for retention of effector CD8 T cells in mouse lungs. Blood 101: 4916-22.

46. Ray SJ, Franki SN, Pierce RH, Dimitrova S, Koteliansky V, Sprague AG, Doherty PC, de Fougerolles AR, Topham DJ. 2004. The collagen binding alphalbeta1 integrin VLA-1 regulates CD8 T cell-mediated immune protection against heterologous influenza infection. Immunity 20: 167-79. 
47. Xu B, Wagner N, Pham LN, Magno V, Shan Z, Butcher EC, Michie SA. 2003. Lymphocyte homing to bronchus-associated lymphoid tissue (BALT) is mediated by L-selectin/PNAd, alpha4beta1 integrin/VCAM-1, and LFA-1 adhesion pathways. $J$ Exp Med 197: 1255-67.

48. Campbell JJ, Brightling CE, Symon FA, Qin S, Murphy KE, Hodge M, Andrew DP, Wu L, Butcher EC, Wardlaw AJ. 2001. Expression of chemokine receptors by lung T cells from normal and asthmatic subjects. J Immunol 166: 2842-8.

49. Kohlmeier JE, Cookenham T, Miller SC, Roberts AD, Christensen JP, Thomsen AR, Woodland DL. 2009. CXCR3 directs antigen-specific effector CD4+ T cell migration to the lung during parainfluenza virus infection. J Immunol 183: 4378-84.

50. Kohlmeier JE, Miller SC, Smith J, Lu B, Gerard C, Cookenham T, Roberts AD, Woodland DL. 2008. The chemokine receptor CCR5 plays a key role in the early memory CD8+ T cell response to respiratory virus infections. Immunity 29: 101-13.

51. Ross PJ, Lavelle EC, Mills KH, Boyd AP. 2004. Adenylate cyclase toxin from Bordetella pertussis synergizes with lipopolysaccharide to promote innate interleukin-10 production and enhances the induction of Th2 and regulatory T cells. Infect Immun 72: 1568-79.

52. Picker LJ, Martin RJ, Trumble A, Newman LS, Collins PA, Bergstresser PR, Leung DY. 1994. Differential expression of lymphocyte homing receptors by human memory/effector T cells in pulmonary versus cutaneous immune effector sites. Eur $J$ Immunol 24: 1269-77. 
CHAPTER III

CONCLUSION 


\section{Conclusions}

These experiments were designed to study the interactions between DCs and CD4+ T cells that lead to the imprinting of trafficking markers, which are especially important for respiratory illnesses such as B. pertussis. The discovery of lung specific trafficking markers will aid in the development of improved vaccines that target the upregulation of such molecules and will enhance the clearance of respiratory pathogens. Our results from this research project indicated that DCs are activated and adopt a mature phenotype from $B$. pertussis infection on day 5, and that perhaps PTx interferes with the imprinting process, as observed by the downregulation of CD11a and CD162 on CD4+ T cells, which are important molecules for T cell retention in the lungs. However, 25 days post-infection with $B$. pertussis there is continued elevated expression of MHC class II, CCR5, and CD11b in addition to upregulation of CD11a and CD49d, which could be due to the fading effects of PTx. This suggests that $B$. pertussis may initially alter the DC imprinting process to avoid $\mathrm{T}$ cell recruitment to the lungs.

\section{Future directions}

In order to further investigate the effects $B$. pertussis has on the respiratory system, we plan to perform immunohistochemical analysis of lung sections from uninfected and Bordetella-infected mice. These lung sections will illustrate the degree of inflammation and tissue damage inflicted by the bacteria compared to uninfected lungs. We will also include fluorescence tagged antibodies specific to $\mathrm{T}$ cells to determine whether these cells are recruited to the lungs. In order to broaden our analysis of 
lymphocyte trafficking we will also incorporate CD8+ T cells to observe whether PTx differentially imprints homing molecules on this cell type during infection. 


\section{REFERENCES}

1. Butcher EC, Picker LJ. 1996. Lymphocyte homing and homeostasis. Science 272: 606.

2. Carbonetti NH. 2007. Immunomodulation in the pathogenesis of Bordetella pertussis infection and disease. Curr Opin Pharmacol 7: 272-8.

3. McIntyre P, Wood N. 2009. Pertussis in early infancy: disease burden and preventive strategies. Curr Opin Infect Dis 22: 215-23.

4. Mattoo S, Cherry JD. 2005. Molecular pathogenesis, epidemiology, and clinical manifestations of respiratory infections due to Bordetella pertussis and other Bordetella subspecies. Clin Microbiol Rev 18: 326-82.

5. Crowcroft NS, Pebody RG. 2006. Recent developments in pertussis. Lancet 367: 1926-36.

6. Pertussis. Department of Health and Human Services. 2009. Centers for Disease Control and Prevention. 19 Feb 2010.

<http://www.cdc.gov/ncidod/dbmd/Diseaseinfo/pertussis_t.htm>.

7. Bernales R, Eastman J, Kaplan J. 1976. Quantitation of circulating T and B lymphocytes in children with whooping cough. Pediatr Res 10: 965-7.

8. Mooi FR. 1988. Virulence factors of Bordetella pertussis. Antonie Van Leeuwenhoek 54: 465-74.

9. Munoz JJ, Arai H, Bergman RK, Sadowski PL. 1981. Biological activities of crystalline pertussigen from Bordetella pertussis. Infect Immun 33: 820-6.

10. Pittman M. 1979. Pertussis toxin: the cause of the harmful effects and prolonged immunity of whooping cough. A hypothesis. Rev Infect Dis 1: 401-12. 
11. Kohlmeier JE, Woodland DL. 2009. Immunity to respiratory viruses. Annu Rev Immunol 27: 61-82.

12. Weiner HL. 2004. Tolerogenic dendritic cells and T regulatory cells in the mucosa. Sociedade Brasileira de Imunologia. 24 Mar 2009 <http://www.sbi.org.br/sbinarede/SBInarede25/howard.htm>.

13. Mills KH. 2001. Immunity to Bordetella pertussis. Microbes Infect 3: 655-77.

14. Smith AM, Guzman CA, Walker MJ. 2001. The virulence factors of Bordetella pertussis: a matter of control. FEMS Microbiol Rev 25: 309-33.

15. Aepfelbacher M, Aktories K, Just I. 2000. Bacterial protein toxins. Berlin ; New York: Springer. xxxii, p. 167-185.

16. Andreasen C, Carbonetti NH. 2008. Pertussis toxin inhibits early chemokine production to delay neutrophil recruitment in response to Bordetella pertussis respiratory tract infection in mice. Infect Immun 76: 5139-48.

17. Carbonetti NH, Artamonova GV, Andreasen C, Bushar N. 2005. Pertussis toxin and adenylate cyclase toxin provide a one-two punch for establishment of Bordetella pertussis infection of the respiratory tract. Infect Immun 73: 2698-703.

18. Carbonetti NH, Artamonova GV, Mays RM, Worthington ZE. 2003. Pertussis toxin plays an early role in respiratory tract colonization by Bordetella pertussis. Infect Immun 71: 6358-66.

19. Kirimanjeswara GS, Agosto LM, Kennett MJ, Bjornstad ON, Harvill ET. 2005. Pertussis toxin inhibits neutrophil recruitment to delay antibody-mediated clearance of Bordetella pertussis. J Clin Invest 115: 3594-601.

20. Meade BD, Kind PD, Ewell JB, McGrath PP, Manclark CR. 1984. In vitro inhibition of murine macrophage migration by Bordetella pertussis lymphocytosis-promoting factor. Infect Immun 45: 718-25. 
21. Holt PG, Strickland DH, Wikstrom ME, Jahnsen FL. 2008. Regulation of immunological homeostasis in the respiratory tract. Nat Rev Immunol 8: 142-52.

22. Jahnsen FL, Strickland DH, Thomas JA, Tobagus IT, Napoli S, Zosky GR, Turner DJ, Sly PD, Stumbles PA, Holt PG. 2006. Accelerated antigen sampling and transport by airway mucosal dendritic cells following inhalation of a bacterial stimulus. $J$ Immunol 177: 5861-7.

23. Kim CH, Campbell DJ, Butcher EC. 2001. Nonpolarized memory T cells. Trends Immunol 22: 527-30.

24. Sallusto F, Mackay CR, Lanzavecchia A. 2000. The role of chemokine receptors in primary, effector, and memory immune responses. Апnи Rev Immunol 18: 593-620.

25. Mora JR. 2008. Homing imprinting and immunomodulation in the gut: role of dendritic cells and retinoids. Inflamm Bowel Dis 14: 275-89.

26. Sigmundsdottir H, Butcher EC. 2008. Environmental cues, dendritic cells and the programming of tissue-selective lymphocyte trafficking. Nat Immunol 9: 981-7.

27. Abitorabi MA, Mackay CR, Jerome EH, Osorio O, Butcher EC, Erle DJ. 1996. Differential expression of homing molecules on recirculating lymphocytes from sheep gut, peripheral, and lung lymph. J Immunol 156: 3111-7.

28. Butcher EC, Williams M, Youngman K, Rott L, Briskin M. 1999. Lymphocyte trafficking and regional immunity. Adv Immunol 72: 209-53.

29. Iwata M, Hirakiyama A, Eshima Y, Kagechika H, Kato C, Song SY. 2004. Retinoic acid imprints gut-homing specificity on T cells. Immunity 21: 527-38.

30. Kunkel EJ, Campbell JJ, Haraldsen G, Pan J, Boisvert J, Roberts AI, Ebert EC, Vierra MA, Goodman SB, Genovese MC, Wardlaw AJ, Greenberg HB, Parker CM, Butcher EC, Andrew DP, Agace WW. 2000. Lymphocyte CC chemokine receptor 9 and epithelial thymus-expressed chemokine (TECK) expression distinguish the small 
intestinal immune compartment: Epithelial expression of tissue-specific chemokines as an organizing principle in regional immunity. J Exp Med 192: 761-8.

31. Campbell JJ, Haraldsen G, Pan J, Rottman J, Qin S, Ponath P, Andrew DP, Warnke R, Ruffing N, Kassam N, Wu L, Butcher EC. 1999. The chemokine receptor CCR4 in vascular recognition by cutaneous but not intestinal memory T cells. Nature 400: 776-80.

32. Reiss Y, Proudfoot AE, Power CA, Campbell JJ, Butcher EC. 2001. CC chemokine receptor (CCR)4 and the CCR10 ligand cutaneous T cell-attracting chemokine (CTACK) in lymphocyte trafficking to inflamed skin. J Exp Med 194: 1541-7.

33. Sigmundsdottir H, Pan J, Debes GF, Alt C, Habtezion A, Soler D, Butcher EC. 2007. DCs metabolize sunlight-induced vitamin D3 to 'program' T cell attraction to the epidermal chemokine CCL27. Nat Immunol 8: 285-93.

34. de Bree GJ, van Leeuwen EM, Out TA, Jansen HM, Jonkers RE, van Lier RA. 2005. Selective accumulation of differentiated CD8+ T cells specific for respiratory viruses in the human lung. J Exp Med 202: 1433-42.

35. Arico B, Gross R, Smida J, Rappuoli R. 1987. Evolutionary relationships in the genus Bordetella. Mol Microbiol 1: 301-8.

36. Arico B, Rappuoli R. 1987. Bordetella parapertussis and Bordetella bronchiseptica contain transcriptionally silent pertussis toxin genes. J Bacteriol 169: 2847-53.

37. Wolfe DN, Kirimanjeswara GS, Harvill ET. 2005. Clearance of Bordetella parapertussis from the lower respiratory tract requires humoral and cellular immunity. Infect Immun 73: 6508-13.

38. Zachariadis O, Cassidy JP, Brady J, Mahon BP. 2006. Gammadelta T cells regulate the early inflammatory response to Bordetella pertussis infection in the murine respiratory tract. Infect Immun 74: 1837-45. 
39. Campanelli AP, Roselino AM, Cavassani KA, Pereira MS, Mortara RA, Brodskyn CI, Goncalves HS, Belkaid Y, Barral-Netto M, Barral A, Silva JS. 2006.

CD4+CD25+ T cells in skin lesions of patients with cutaneous leishmaniasis exhibit phenotypic and functional characteristics of natural regulatory T cells. J Infect Dis 193: 1313-22.

40. Gonzalez-Juarrero M, Shim TS, Kipnis A, Junqueira-Kipnis AP, Orme IM. 2003. Dynamics of macrophage cell populations during murine pulmonary tuberculosis. $J$ Immunol 171: 3128-35.

41. Dunne PJ, Moran B, Cummins RC, Mills KH. 2009. CD11c+CD8alpha+ dendritic cells promote protective immunity to respiratory infection with Bordetella pertussis. $J$ Immunol 183: 400-10.

42. Suffia I, Reckling SK, Salay G, Belkaid Y. 2005. A role for CD103 in the retention of CD4+CD25+ Treg and control of Leishmania major infection. J Immunol 174: 544455.

43. Clark JG, Mandac-Dy JB, Dixon AE, Madtes DK, Burkhart KM, Harlan JM, Bullard DC. 2004. Trafficking of Th1 cells to lung: a role for selectins and a P-selectin glycoprotein-1-independent ligand. Am J Respir Cell Mol Biol 30: 220-7.

44. Ghosh S, Chackerian AA, Parker CM, Ballantyne CM, Behar SM. 2006. The LFA-1 adhesion molecule is required for protective immunity during pulmonary Mycobacterium tuberculosis infection. J Immunol 176: 4914-22.

45. Thatte J, Dabak V, Williams MB, Braciale TJ, Ley K. 2003. LFA-1 is required for retention of effector CD8 T cells in mouse lungs. Blood 101: 4916-22.

46. Ray SJ, Franki SN, Pierce RH, Dimitrova S, Koteliansky V, Sprague AG, Doherty PC, de Fougerolles AR, Topham DJ. 2004. The collagen binding alphalbeta1 integrin VLA-1 regulates CD8 T cell-mediated immune protection against heterologous influenza infection. Immunity 20: 167-79. 
47. Xu B, Wagner N, Pham LN, Magno V, Shan Z, Butcher EC, Michie SA. 2003. Lymphocyte homing to bronchus-associated lymphoid tissue (BALT) is mediated by L-selectin/PNAd, alpha4beta1 integrin/VCAM-1, and LFA-1 adhesion pathways. $J$ Exp Med 197: 1255-67.

48. Campbell JJ, Brightling CE, Symon FA, Qin S, Murphy KE, Hodge M, Andrew DP, Wu L, Butcher EC, Wardlaw AJ. 2001. Expression of chemokine receptors by lung T cells from normal and asthmatic subjects. J Immunol 166: 2842-8.

49. Kohlmeier JE, Cookenham T, Miller SC, Roberts AD, Christensen JP, Thomsen AR, Woodland DL. 2009. CXCR3 directs antigen-specific effector CD4+ T cell migration to the lung during parainfluenza virus infection. J Immunol 183: 4378-84.

50. Kohlmeier JE, Miller SC, Smith J, Lu B, Gerard C, Cookenham T, Roberts AD, Woodland DL. 2008. The chemokine receptor CCR5 plays a key role in the early memory CD8+ T cell response to respiratory virus infections. Immunity 29: 101-13.

51. Ross PJ, Lavelle EC, Mills KH, Boyd AP. 2004. Adenylate cyclase toxin from Bordetella pertussis synergizes with lipopolysaccharide to promote innate interleukin-10 production and enhances the induction of Th2 and regulatory T cells. Infect Immun 72: 1568-79.

52. Picker LJ, Martin RJ, Trumble A, Newman LS, Collins PA, Bergstresser PR, Leung DY. 1994. Differential expression of lymphocyte homing receptors by human memory/effector T cells in pulmonary versus cutaneous immune effector sites. Eur $J$ Immunol 24: 1269-77. 


\section{APPENDIX A: TIME COURSE EXPERIMENT TO DETERMINE PEAK}

\section{INFECTION}

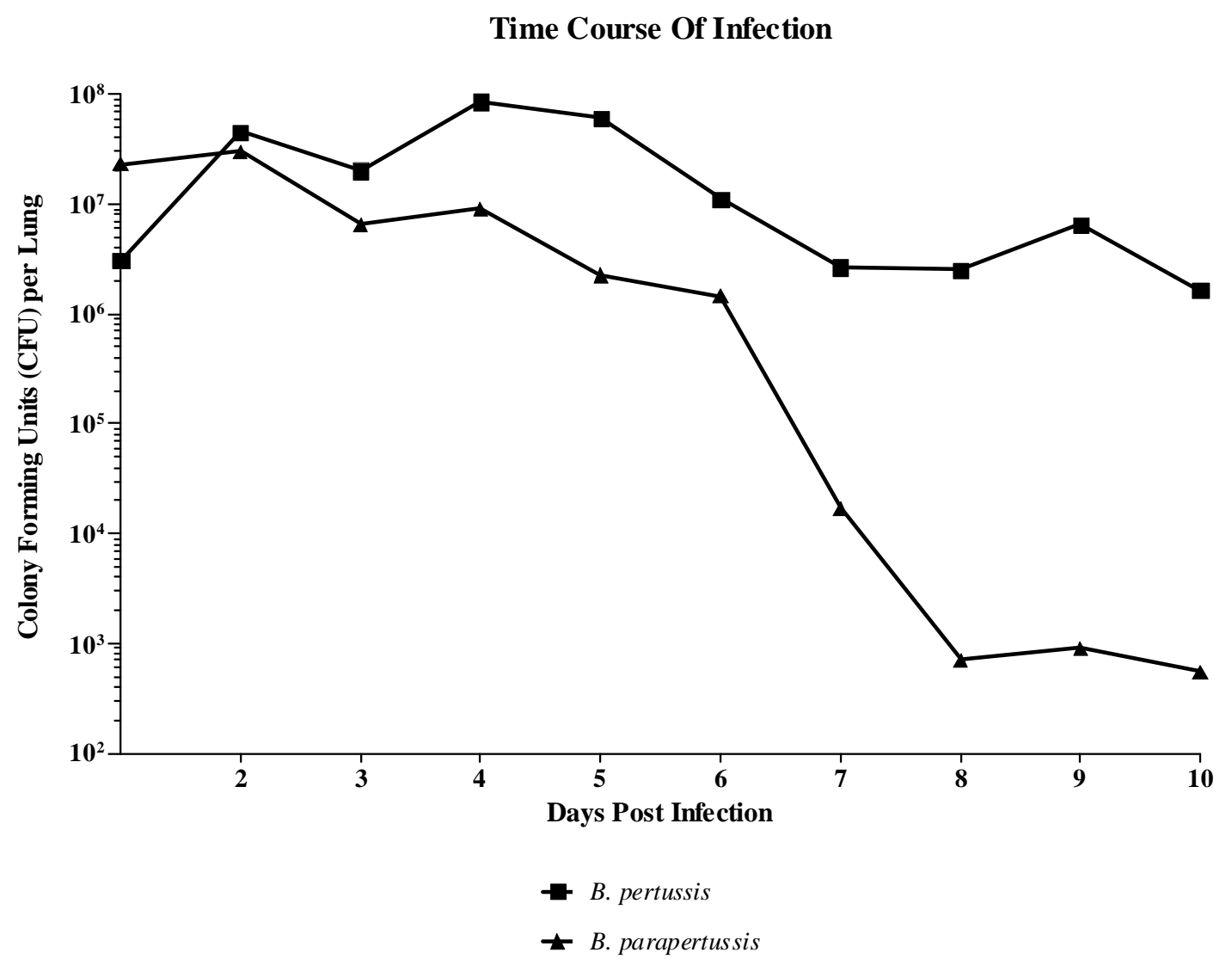

FIGURE 6. A time course of infection shows the peak infection days for B. pertussis and B. parapertussis. In order to determine the optimal day for peak infection, we administered $5 \times 10^{6} \mathrm{CFU}$ per $20 \mu \mathrm{l}$ by intranasal administration and performed a time course experiment with two Balb/c mice per time-point. Lungs were harvested at each time-point, homogenized and plated on Bordet-Gengou blood plates. By day 25 postinfection, zero colonies of $B$. pertussis and B. parapertussis were recovered from lungs (data not shown). Experiment and analysis was done by Nicole Tarlton. 
APPENDIX B: SUPPLEMENTARY DATA

7A

Percent CD11c+ Cells per Treatment

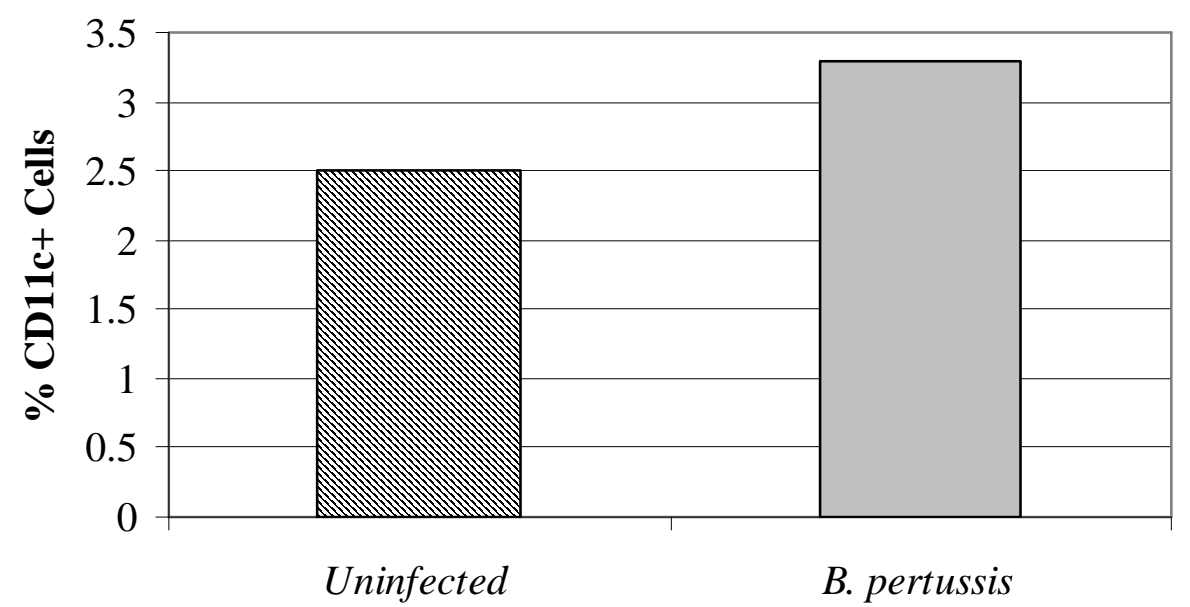

Treatment

FIGURE 7. DCs mature in response to B. pertussis infection even with smaller doses of inoculum. BALB/c mice were infected intranasally with $5 \times 10^{5} \mathrm{CFU}$ in $20 \mu \mathrm{l}$ and percent DCs were measured in each treatment at a peak infection time of 10 days $(A)$. Maturation markers (MHC class II, CD40, CD86) and lung-associated markers (CD11b, CD207) were also measured $(B)$. Bordetella pertussis-infected DCs were co-cultured with naïve splenocytes and levels of CCR5, CCR6, CD103, CD106, CD11a, CD162, CD49d, and CD49f were assessed $(C)$. All values for the co-cultures were normalized to uninfected controls $(100 \%)$. 
APPENDIX B: SUPPLEMENTARY DATA

7B

DC Maturation During Peak Infection

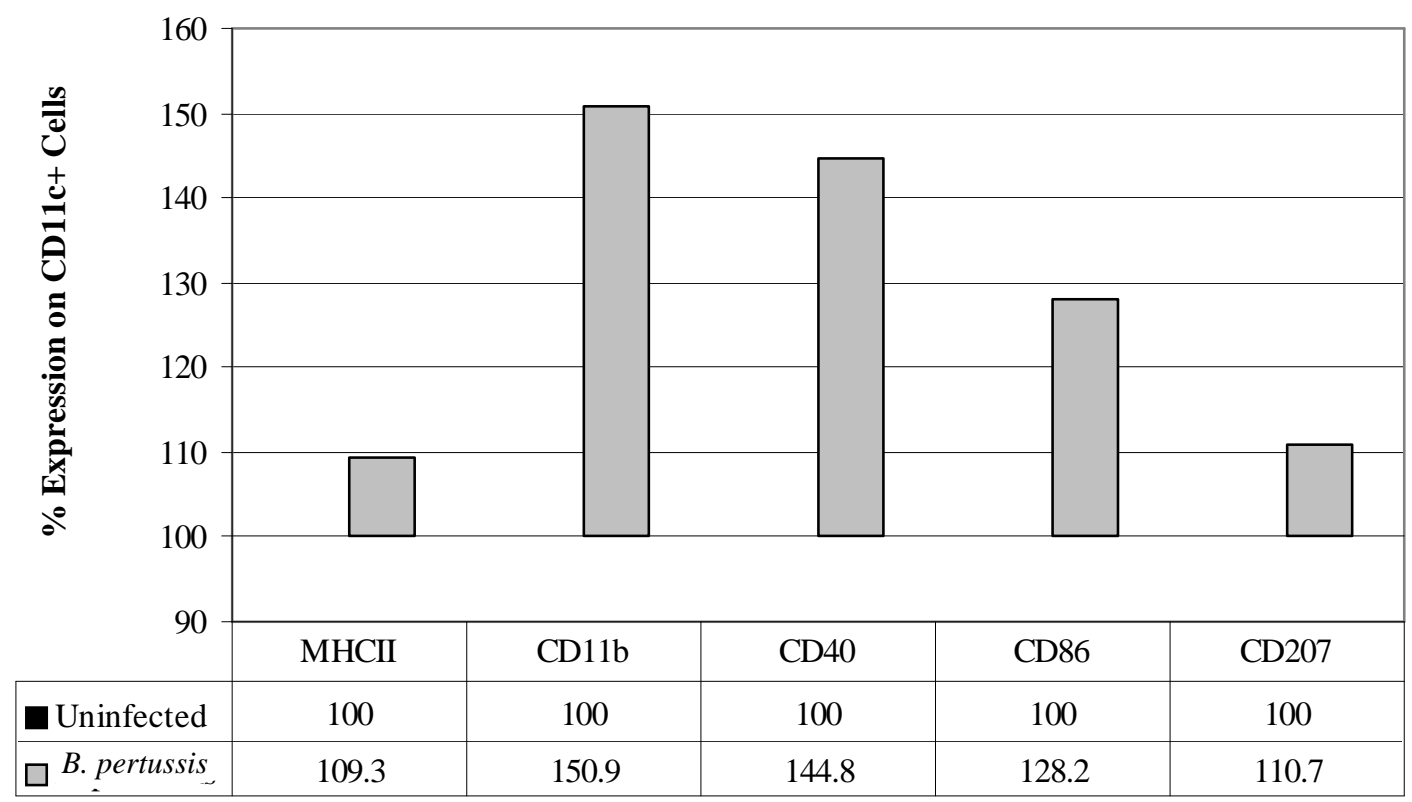

7C

Trafficking Molecule Expression During Peak Infection

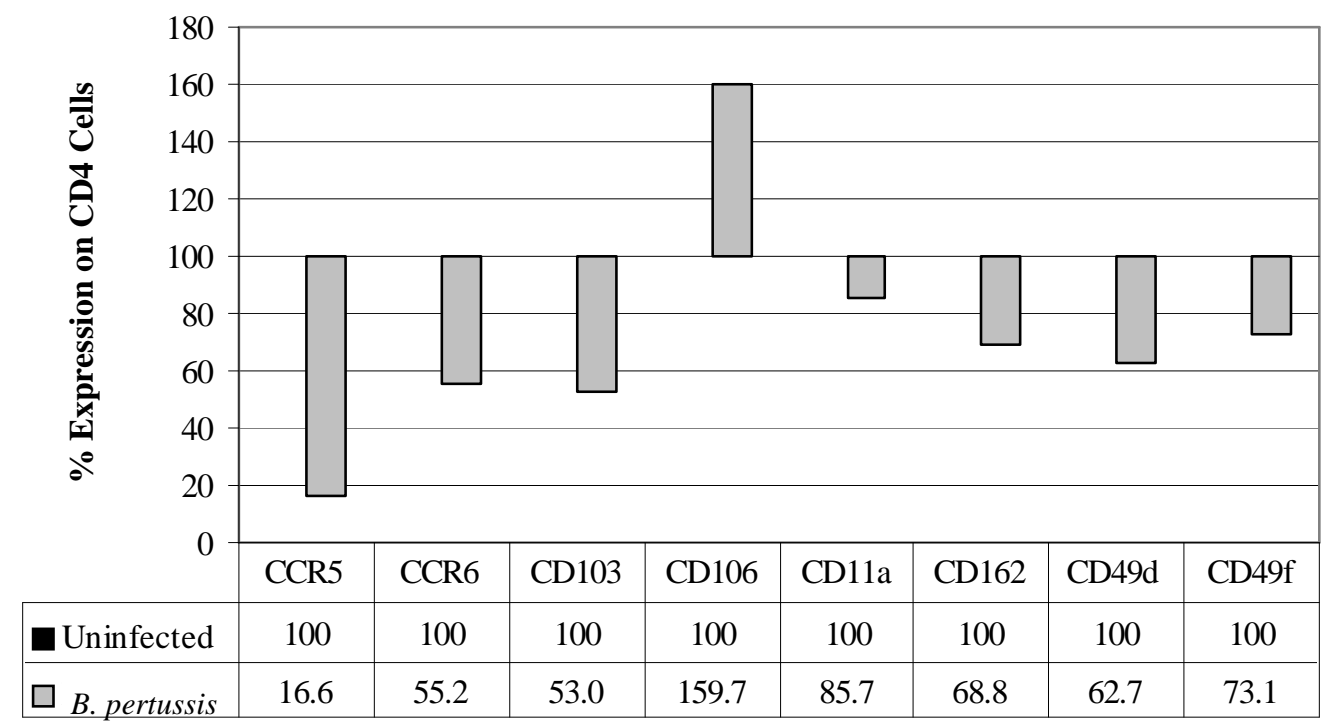




\title{
APPENDIX B: SUPPLEMENTARY DATA
}

\section{A}

\author{
Percent CD11c+ Cells per Treatment
}

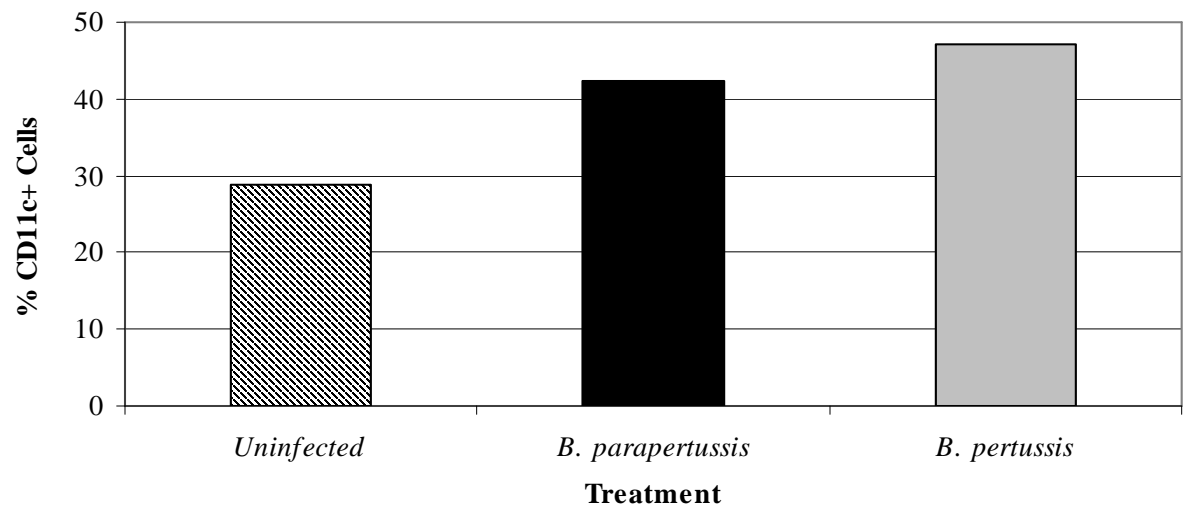

FIGURE 8. DCs mature in response to Bordetella and downregulation of homing molecules on CD4+ T cells was observed in B. pertussis co-cultures. We assessed the percentage of $\mathrm{CD} 11 \mathrm{c}+$ cells in each treatment using quadrants that were placed according to positive controls $(A)$. DC maturation markers observed included MHC class II, CD40, CD80, CD86; myeloid and lung associated markers, CD11b, CD207 and migratory makers CD103, CCR5, CCR6, CCR7 (B). After co-culturing, levels of the chemokine receptors CCR5, CCR6, CXCR3, and adhesion markers CD11a, CD29, CD49a, CD49d, CD106, and CD162 were measured $(C)$. All values were normalized to uninfected controls $(100 \%)$. 
APPENDIX B: SUPPLEMENTARY DATA
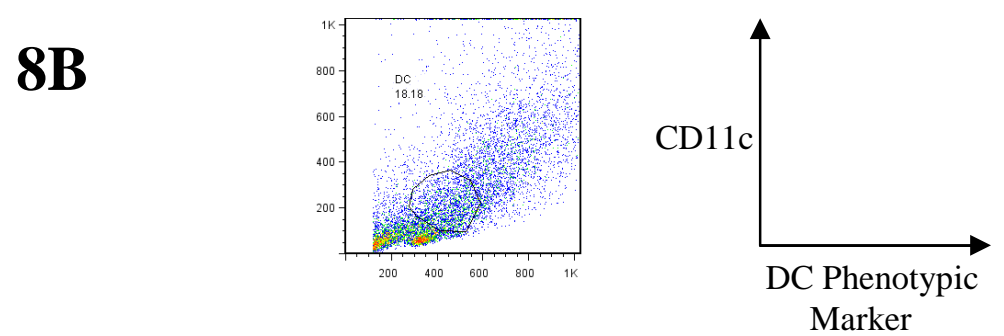

Uninfected
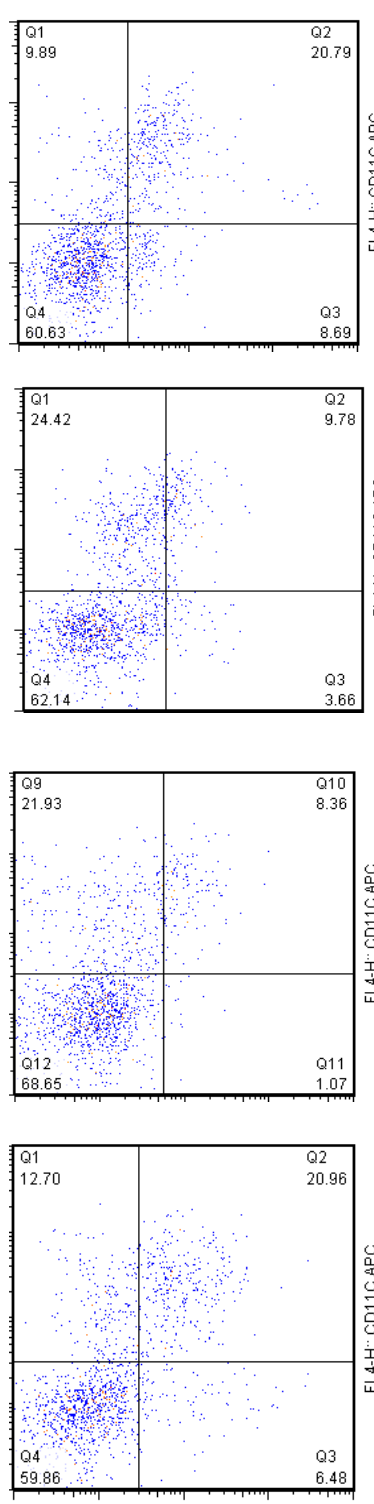

B. parapertussis
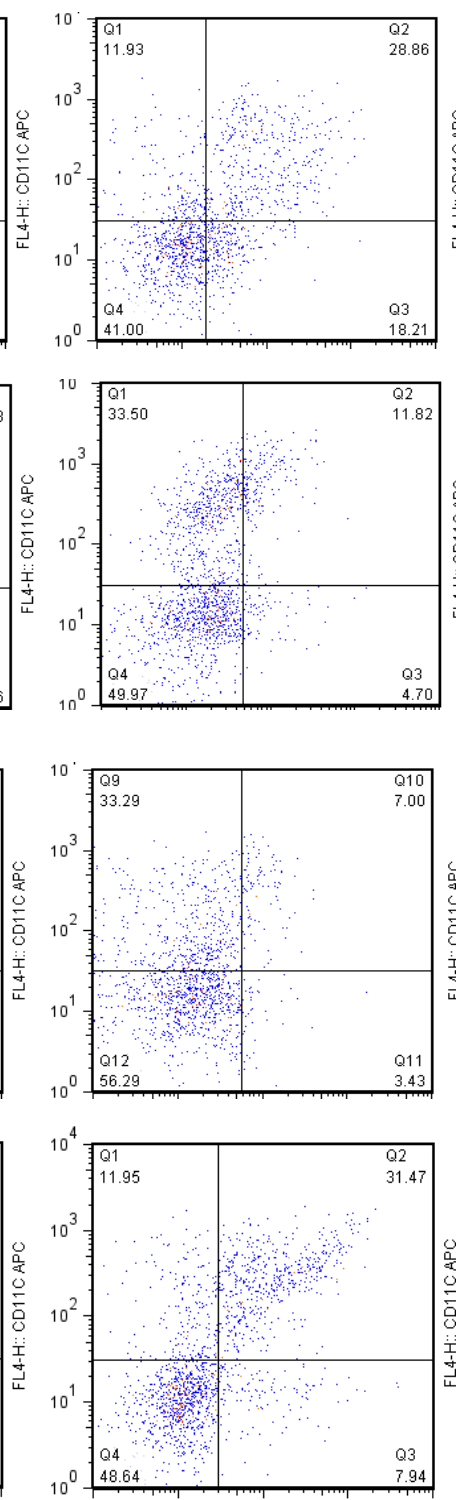

B. pertussis

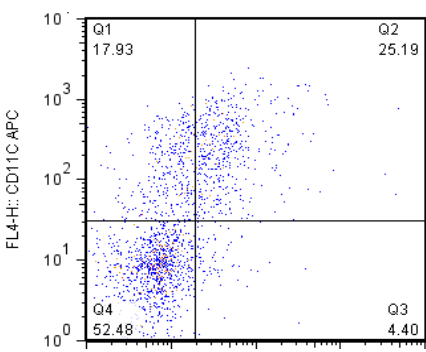

CD40

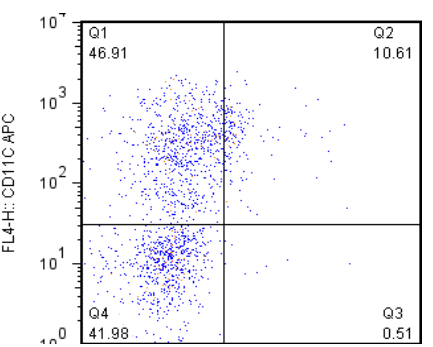

CD207

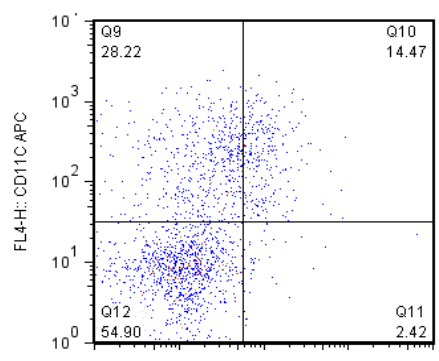

CD86

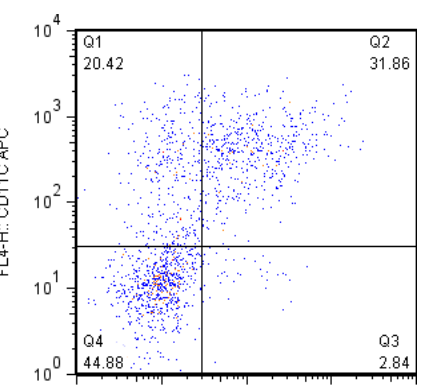

CCR5 


\section{APPENDIX B: SUPPLEMENTARY DATA}
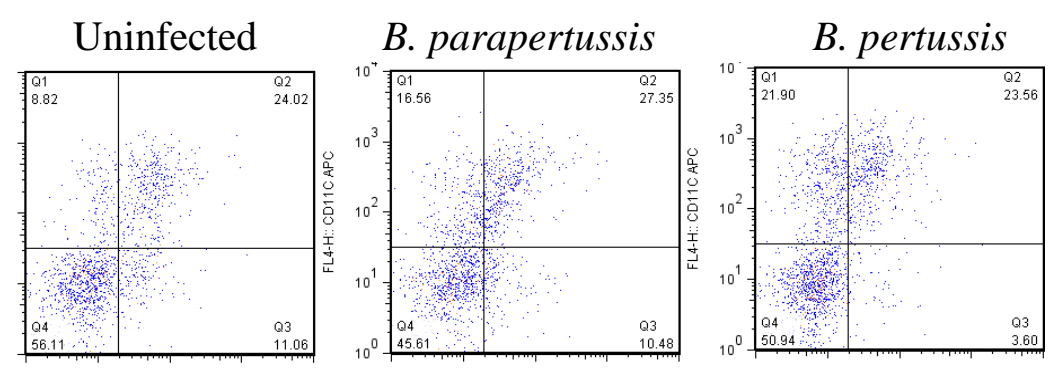

CCR6
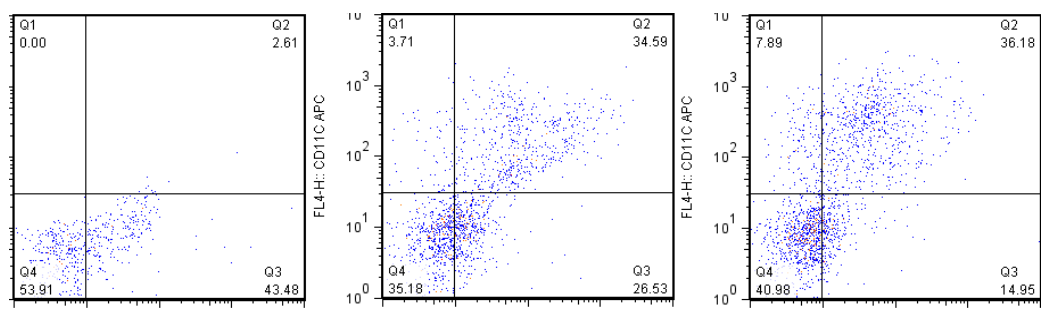

CD103
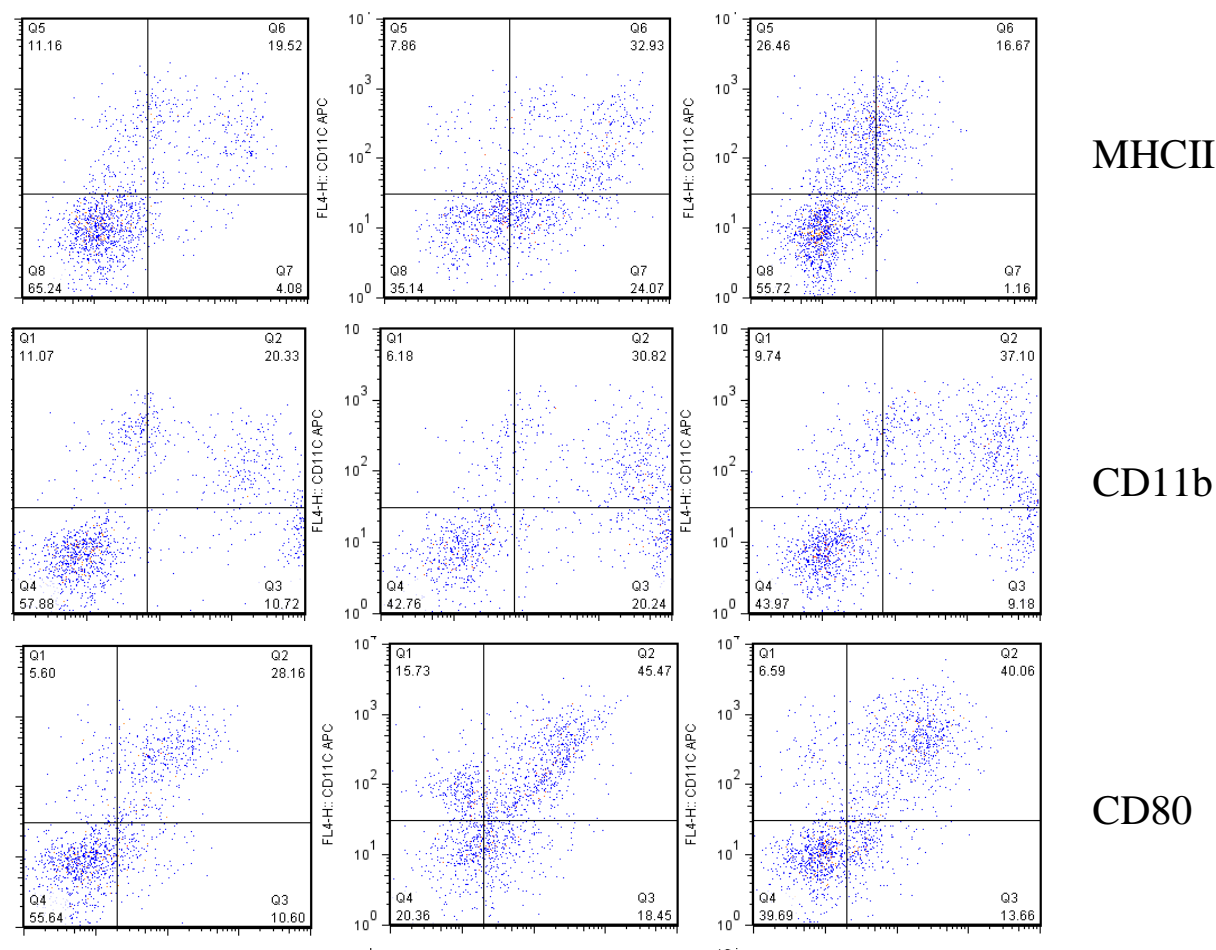

MHCII
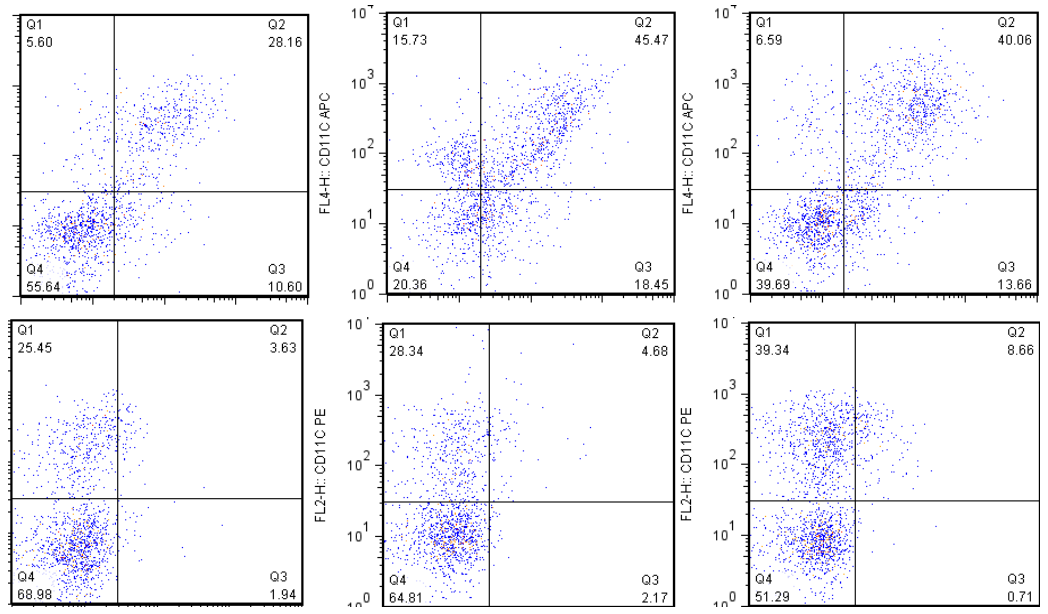

CD80

CCR7 


\section{APPENDIX B: SUPPLEMENTARY DATA}

\section{C}

Trafficking Molecules Expression During Peak Infection

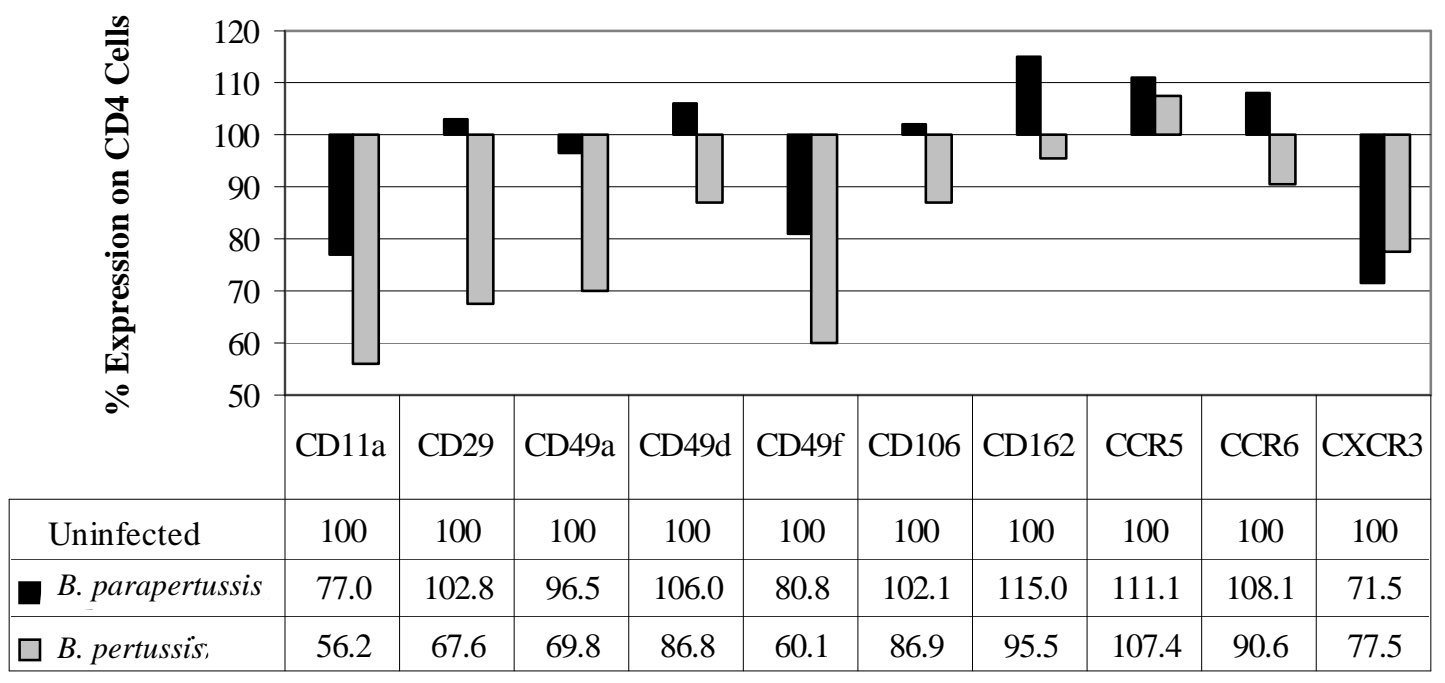




\section{APPENDIX B: SUPPLEMENTARY DATA}

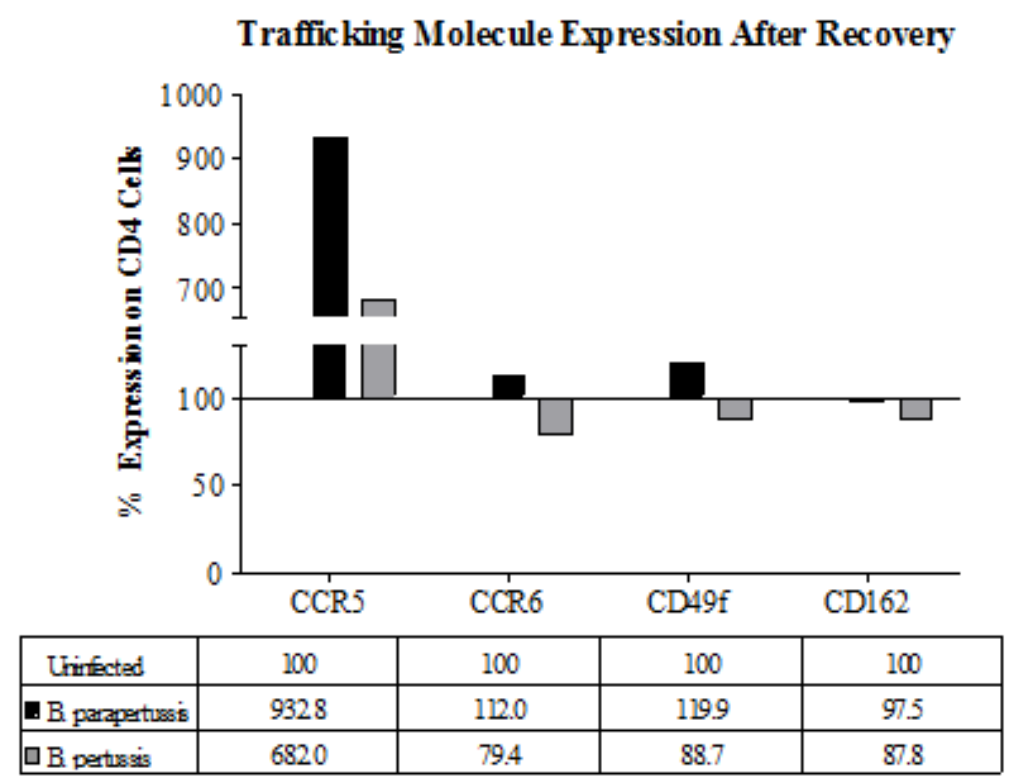

FIGURE 9. 25 days post-infection, the pattern of trafficking markers changes compared to peak infection. 25 days after infection with Bordetella, levels of CCR5, CCR6, CD49f, and CD162 were measured on co-cultured CD4+ T cell. All values were normalized to uninfected controls $(100 \%)$. 